\title{
A Subtidal Box Model based on the Longitudinal Anomaly of Potential Energy for Narrow Estuaries. An Application to the Guadalquivir River Estuary (SW Spain).
}

\author{
M. Cobos $^{1}$, A. Baquerizo ${ }^{1}$, M. Díez-Minguito ${ }^{1}$, and M.A. Losada ${ }^{1}$ \\ ${ }^{1}$ Andalusian Institute for Earth System Research, University of Granada, Avda. del Mediterráneo s/n, \\ 18006, Granada, Spain
}

\section{Key Points:}

- A balance equation of the longitudinal anomaly of the potential energy (LAPE) was derived.

- The balance was applied in boxes to the GRE and explains the salt intrusion and turbidity maxima.

- The dominant LAPE transports in the GRE vary spatially and also depend on the hydraulic regime. 


\begin{abstract}
The objective of the present study is to demonstrate the informative capacity of the longitudinal anomaly of potential energy (LAPE) in the analysis of the magnitude and spatiotemporal variability of estuarine processes. For this purpose, a LAPE balance equation is formulated. The LAPE integrates and varies with the vertical and longitudinal density distribution. The formulation is applied on a subtidal scale to each box or stretch of the Guadalquivir River estuary, a narrow, highly turbid, weakly stratified, and strongly anthropized estuary. Data recorded by a large network of monitoring stations in 2008 and 2009 are used to quantify advective transports as well as the transports associated with longitudinal dispersion and vertical turbulent mixing in different hydraulic regimes. In low-river flow conditions, (river flows $Q<40 \mathrm{~m}^{3} \mathrm{~s}^{-1}$ ), the magnitude of LAPE transports decreases upstream and varies locally, depending on neap-spring tidal cycles. The direction of the net LAPE transport creates convergence zones that are particularly consistent with maximum levels of estuarine turbidity. During high-river flows $\left(Q>400 \mathrm{~m}^{3} \mathrm{~s}^{-1}\right)$, this convergence disappears and the maximum longitudinal density gradient moves towards the mouth. More specifically, tidal pumping -induced LAPE governs during these conditions and manages to compensate the sum of the mean non-tidal and dispersive and differential advective LAPE transports. However, during the post-riverflood period, the mechanisms controlling recovery downstream from the mouth are the longitudinal dispersive and differential advective LAPE transports. Furthermore, the convergence zone reappears with a longitudinal gradient of the net LAPE transport that is even greater than in low-river flow conditions.
\end{abstract}

\title{
1 Introduction
}

\subsection{Knowledge integration and simplification for estuary management}

Human action is the main reason why many estuaries have experienced significant changes in recent decades. Such changes include: (i) modification of their hydrographic basins because of water diverted for irrigation, and the damming of the main water course and its tributaries; (ii) industrial and farming activities on their banks; and (iii) changes in estuary geometry because of depth and maintenance dredging (e.g.) (Hobbie, 2000; Ruiz et al., 2015; Reyes-Merlo et al., 2017). The anthropization of an estuary alters its biochemical and physical dynamics by modifying nutrient mixing as well as the sediment and oxygen transport in water bodies adjacent to rivers and seas (Simpson \& Sharples, 2012; Officer, 2013).

In certain estuaries, such as the Guadalquivir River Estuary (SW Spain), these interventions are reflected in changes in hydro-morphodynamics all along the estuary as well as in different hydraulic regimes of the fluvial agents (low-river flow, high-river flow, and post-riverflood recovery) and marine agents (neap and spring tides) (Ruiz et al., 2015). From an estuary management perspective, it is a considerable challenge to integrate this scientific evidence in simple, manageable models such as box models that are capable of quantifying the effects of such changes on estuarine dynamics. Box models are generally used to describe processes and to establish balances based on volumetric averages of the main oceanographic and estuarine variables with a suitable spatiotemporal scale (Officer, 1980; Hamilton et al., 1985; Austin, 2002; Rice et al., 2008; Díez-Minguito et al., 2014; Sun et al., 2017). This type of model can facilitate decision-making based on knowledge of the sustainable use of the estuary (Leschine et al., 2003).

Such decisions should be regulated by a legal framework such as the Water Framework Directive 2000/60/EC (WFD), which establishes the need to adopt measures to protect and improve transitional water bodies, such as estuaries, whose quality depends on their ecological status (Ganju et al., 2016). The WFD describes the ecological status of an estuary in terms of the values of hydromorphological parameters, such as the 
current velocity, salinity, temperature, turbidity and mixing characteristics, among others.

\subsection{Longitudinal Anomaly of Potential Energy (LAPE)}

The potential energy anomaly is a magnitude that integrates those hydromorphological parameters (Simpson \& Hunter, 1974; Simpson, 1981; Simpson et al., 1990). In energy terms, the potential energy anomaly, $\phi_{S}\left(\mathrm{Jm}^{-3}\right)$, quantifies the water column stratification and is defined as the amount of mechanical energy per $\mathrm{m}^{3}$ needed to instantaneously homogenize the water column (Simpson, 1981). This is mathematically expressed as follows:

$$
\phi_{S}(\mathbf{x}, t)=\frac{g}{d} \int_{-h}^{\eta}(\rho-\underline{\rho}) z d z, \quad \text { where } \quad \underline{\rho}(\mathbf{x}, t)=\frac{1}{d} \int_{-h}^{\eta} \rho d z,
$$

where $g$ is the gravity constant; $t$ is the time; $\mathbf{x}$ defines the horizontal position; $z$, represents the vertical coordinate; $\rho(\mathbf{x}, z, t)$ is the water density, and $\rho(\mathbf{x}, t)$ is the reference density in complete mixing conditions, both of which include the suspended sediment density; $d$ is the total depth that is the sum of $\eta(\mathbf{x}, t)$, the elevation over mean sea level and $h(\mathbf{x})$, the mean depth. From the time when it was first proposed in the mid 1970s (Simpson \& Hunter, 1974), the potential energy anomaly has been widely used to identify physical processes that produce water exchanges in shelf seas (Simpson et al., 1990; Hofmeister et al., 2009; Yang et al., 2017), regions influenced by freshwater (Simpson, 1997; De Boer et al., 2008), estuaries (Garvine \& Whitney, 2006; Rice et al., 2008; Sun et al., 2017), and lakes (Zhao et al., 2018).

Crucial to the present research study is the work of Garvine and Whitney (2006) (GW2006), who used the potential energy anomaly to calculate the flow exchanges between the Delaware estuary and the adjacent continental shelf. The work of GW2006 establishes the potential energy anomaly budget in which the reference density is at a point, $\mathbf{x}_{\mathbf{0}}$ located downstream on the continental shelf instead of the mean density in the water column (eq. 1). The definition of $\phi$ in GW2006 is henceforth referred to as the Longitudinal Anomaly of Potential Energy (LAPE) and is formulated as follows:

$$
\phi(\mathbf{x}, t)=\frac{g}{d} \int_{-h}^{\eta}\left(\rho-\underline{\rho_{0}}\right) z d z, \quad \text { where } \quad \underline{\rho_{0}}=\frac{1}{d} \int_{-h}^{\eta} \rho\left(\mathbf{x}_{\mathbf{0}}, t\right) d z,
$$

where $\rho_{0}$ is the mean density of slope water beyond the shelf at the location $\mathbf{x}_{\mathbf{0}}$. This density is the reference density in complete mixing conditions, which are in this case, longitudinal. GW2006 represents the characteristics of the system with a single box to represent the estuary, which is directly connected to the continental platform at the subtidal scale. They considered the change rate in the LAPE as induced by freshwater inflow, water outflow to the shelf, tidal and wind mixing, and surface heat flux. However in relatively shallow estuaries that are weakly stratified or well-mixed, in addition to gravitational circulations, it is also necessary to consider other contributions to the LAPE, such as those associated with longitudinal dispersion, tidal pumping, and differential advection (van Aken, 1986; Burchard \& Hetland, 2010; Becherer et al., 2016). Differential advection includes two terms. The first term is associated with depth-mean straining due to the vertical mean horizontal density gradient strained by the deviation from the depthmean velocity vector (depth-mean straining). The second term is associated with the deviations of the longitudinal velocities and the gradient of density deviations (non-depthmean straining) (Burchard \& Hofmeister, 2008).

\subsection{Objectives and Organization}

The objective of this research was to evaluate the joint spatiotemporal variability of state variables in the WFD, such as density. This includes the contribution of the suspended solids concentration and the flow velocity throughout the estuary and in different fluvial regimes (i.e. low-river flow, high-river flow, and post-riverflood recovery) and 
tidal regimes (neap and spring tides). This study led to the formulation of a subtidalscale dynamic equation that is able to evaluate the Longitudinal Anomaly of Potential Energy (LAPE), and which integrates the previously mentioned state variables and the transports that control them. This equation includes the impact of intratidal processes on the subtidal scale by means of the tidal decomposition method (Díez-Minguito et al., 2013; Scully \& Friedrichs, 2007; Becherer et al., 2016; Burchard et al., 2018). It also extends the work of Garvine and Whitney (2006) by including the influence of the following: (i) longitudinal dispersion; (ii) tidal pumping associated with cross-correlations between density, elevations, and currents; and (iii) differential advection due to depth-mean straining, and non-depth-mean straining. These terms are particularly relevant to narrow estuaries (Jay \& Musiak, 1994; Burchard \& Hetland, 2010).

The LAPE general balance equation was applied to the dynamics of the Guadalquivir River Estuary (GRE). Since the GRE is a narrow, weakly stratified and highly anthropized estuary (Díez-Minguito et al., 2012, 2013, 2014; Ruiz et al., 2015), these same characteristics made it possible to simplify the balance equation and extend Garvine and Whitney (2006) by segmenting the GRE in $N$ boxes. This box model was applied to the GRE over a one-year period with all the previously mentioned hydraulic regimes. To better explain the spatiotemporal variability of the LAPE, we analyzed a high-resolution data set regarding salinity, suspended solids, tidal currents and elevations, and fluvial discharges, which had been recorded in 2008-2009. These data were used to evaluate the LAPE and the different LAPE transport terms in each box.

The rest of this paper is organized as follows. $\S 2$ presents the theoretical derivation of LAPE balance equation. In $\S 3$, the study zone is described, along with the monitoring network and the configuration of the box model. $\S 4$ analyzes the processes observed and relates them to the LAPE and the resulting transports of the model. After Section 5 discusses the results and the validity of the model, Section 6 presents the conclusions derived from this research.

\section{Formulation of the LAPE}

This study focused on a relatively narrow estuary in which the Coriolis effect is negligible and the river flow is transversally uniform (Hansen \& Rattray, 1966; Valle-Levinson, $2008,2010)$. The system of coordinates $(x, z)$ has the origin at the estuary mouth, lying over the mean sea level. The positive $x$-axis follows the thalweg and the $z$-axis points upwards; $d=\eta+h$ is the total depth; $h(x)$, the mean depth of the bed; and $\eta(x, t)$ is the water surface that varies over time, $t$.

\subsection{Interpretation of the LAPE}

According to GW2006, the LAPE, $\phi$, is the mechanical energy per $\mathrm{m}^{3}$ needed to instantaneously homogenize the water mass between sections $x_{0}$ and $x$ (eq. (2)). In weak stratification conditions, the LAPE can be simplified as follows:

$$
\phi(x, t) \simeq \frac{\left[\rho_{0}-\rho(x, t)\right] g d}{2},
$$

with $x_{0}<x$, where $x_{0}$ is located beyond the shelfbreak (Garvine \& Whitney, 2006). As can be observed in eq. (3), calculating $\phi(x, t)$ is the same as calculating the potential energy of the semi-difference of densities between $x$ and $x_{0}$. For a single box, eq. (3) establishes that if the longitudinal density gradient is zero $\left[\rho_{0}=\rho(x, t)\right]$, then $\phi$ is zero. This is the same as finding conditions of complete longitudinal mixing, as can be observed, for example, in tidal river reaches. In normal conditions, density decreases upstream (Officer, 2013) and $\phi>0$. However, in inverse estuaries or in regions where the profile of $\rho(x)$ is locally inverted, density increases upstream and $\phi<0$. 


\subsection{Development of the LAPE balance equation}

The density, $\rho(x, z, t)$, is governed by the balance equation or the dynamic density equation (van Aken, 1986; Burchard \& Hofmeister, 2008) defined as:

$$
\mathbf{D}(x, z, t)=0
$$

where $\mathbf{D}$ is the density equation defined as:

$$
\mathbf{D}(x, z, t)=\partial_{t} \rho+\partial_{x}(u \rho)+\partial_{z}(w \rho)-\partial_{x}\left(k_{x} \partial_{x} \rho\right)-\partial_{z}\left(k_{z} \partial_{z} \rho\right)-\mathbf{S} .
$$

In eq. (5), $\partial_{\chi} \zeta$ denotes the derivative of the generic variable, $\zeta$, in regard to the independent variable $\chi$. The terms $k_{x}$ and $k_{z}$ denote the longitudinal and vertical eddy diffusivities that result from the parameterizations of turbulent fluxes (Burchard \& Hofmeister, 2008). The term $\mathbf{S}(x, z, t)$, encompasses the local source and sink terms, which includes the non-linear effects that appear from the equation of state for sea water (Burchard \& Hofmeister, 2008), the incident solar radiation, and the suspended sediment:

$$
\begin{array}{r}
\mathbf{S}(x, z, t)=k_{x}\left[\partial_{\theta, x}^{2} \rho\left(\partial_{x} \theta\right)^{2}+\partial_{s, x}^{2} \rho\left(\partial_{x} s\right)^{2}\right]+k_{z}\left[\partial_{\theta, z}^{2} \rho\left(\partial_{z} \theta\right)^{2}+\partial_{s, z}^{2} \rho\left(\partial_{z} s\right)^{2}\right] \\
+\frac{g \rho \alpha_{w}}{\rho_{0} c_{p}} I e^{-\varepsilon(\eta-z)}+\left(1-\frac{\rho}{\rho_{s}}\right) C \partial_{z}\left(w_{s} C\right),
\end{array}
$$

where $\partial_{\chi, \varphi}^{2} \zeta=\frac{\partial^{2} \zeta}{\partial \chi \partial \varphi}$; the light penetration in the water column follows the LambertBeer Law, and where $\alpha_{w}$, is the water expansion coefficient; $c_{p}$ is the heat capacity of the water; $\varepsilon$ is the light absorption coefficient; $\rho_{s}$ is the sediment density; $w_{s}$ is the settling velocity; and $C$ is the suspended sediment concentration. Since the values for precipitation, evaporation, and water diverted for irrigation are relative small compared to the fluvial discharges, they are not taken into account. The first term of the RHS in eq. (6) can be usually neglected because it is several orders of magnitude smaller than its counterpart in eq. (5). Assuming weakly-stratified to well-mixed conditions, the second term of the RHS of eq. (6) can also be neglected. This simplification is similar to considering a linear equation of state for seawater.

The dynamic equation of $\phi$ is based on the expressions of $\mathbf{D}$ (eq. (5)), evaluated in $x$ and $x_{0}$, and the equation of the longitudinal anomaly of the potential energy (eq. (2)). When $\mathbf{D}\left(x_{0}, z, t\right)$, is depth-averaged, taking into account the continuity equation, $\partial_{x} u+$ $\partial_{z} w=0$, and the dynamic and kinematic boundary conditions (see Annex), the result is the following:

$$
\begin{array}{r}
\underline{\mathbf{D}\left(x_{0}, t\right)}=\partial_{t}\left(\underline{\left.\rho_{0}\right)}+\partial_{x}\left(\underline{u \rho_{0}}\right)-\partial_{x}\left(\underline{k_{x} \partial_{x} \rho_{0}}\right)-d^{-1}\left[k_{x} \partial_{x} \rho_{0}\right]_{\eta} \partial_{x} \eta-d^{-1}\left[k_{z} \partial_{z} \rho_{0}\right]_{\eta}\right. \\
-d^{-1}\left[k_{x} \partial_{x} \rho_{0}\right]_{-h} \partial_{x} h-d^{-1}\left[k_{z} \partial_{z} \rho_{0}\right]_{-h}-\frac{g \rho \alpha_{w} I}{\rho_{0} c_{p} d}\left(1-e^{-\varepsilon(\eta-z)}\right)-\left(1-\frac{\rho}{\rho_{s}}\right) \frac{w_{s}}{2 d}\left(\left[C^{2}\right]_{\eta}-\left[C^{2}\right]_{-h}\right)
\end{array}
$$

where subindexes $\eta$ and $-h$ indicate the respective surfaces on which the terms $(z=\eta$ and $z=-h$ ) are evaluated. The chain rule is applied to the derivatives and Leibniz"s rule to integrals with variable limits. To calculate the average of $\mathbf{D}\left(x_{0}, t\right)$, each dependent variable $\zeta$ is decomposed in the superposition of the depth-averaged value $\zeta$, and a deviation, $\zeta_{v}$. The same operation is performed with the term $\mathbf{D}(x, t) z$. By substituting the results obtained in eqs. (7) and (A5), the following dynamic equation is obtained for the LAPE:

$$
\begin{aligned}
g\left(\underline{\mathbf{D}\left(x_{0}, t\right)} \underline{z}\right. & -\underline{\mathbf{D}(x, t) z)} \equiv \underbrace{\partial_{t} \phi}_{t_{0}}+\underbrace{g \partial_{x}\left(\left[\underline{\rho_{0}}-\underline{\rho}\right] \underline{u} \underline{z}\right)}_{t_{1}}+\underbrace{\partial_{x}\left(\underline{u} \phi_{S}\right)}_{t_{A}} \\
& -\underbrace{g \partial_{x}\left(\underline{\rho} \underline{u_{v} z}\right)}_{t_{B}}-\underbrace{g \partial_{x}\left(\underline{u_{v}} \underline{\rho_{0}} \underline{z}-\underline{u}_{v} \rho_{v} z\right)}_{t_{C}}+\underbrace{g\left(\underline{w_{v} \rho_{v}}\right)}_{t_{D}}
\end{aligned}
$$




$$
\begin{array}{r}
-\underbrace{g \underline{k}_{z} \partial_{z} \rho}_{t_{E}}+\underbrace{g d^{-1} k_{z}\left(\left[\underline{z} \partial_{z} \rho_{0, v}\right]_{\eta}+\left[\underline{z} \partial_{z} \rho_{0, v}\right]_{-h}\right)}_{t_{F}} \\
-\underbrace{\frac{g \rho \alpha_{w} I}{\rho_{0} c_{p} d}\left[\left(1-e^{-\varepsilon(\eta-z)}\right) \underline{z}+\left(\varepsilon^{-1}-e^{-\varepsilon(\eta-z)}\left(d+\varepsilon^{-1}\right)\right)\right]+\frac{w_{s}}{2 d}\left(\left[C^{2}\right]_{\eta}(1+\eta)-\left[C^{2}\right]_{-h}(1-h)-d \underline{C}\right)}_{t_{G}} \\
+\underbrace{g d^{-1}(\underline{z}-\eta)\left[k_{x} \partial_{x}\left(\underline{\rho}+\rho_{v}\right)\right]_{\eta} \partial_{x} \eta-g d^{-1}(\underline{z}-h)\left[k_{x} \partial_{x}\left(\underline{\rho}+\rho_{v}\right)\right]_{h} \partial_{x} h}_{t_{H}}=0 . \underline{\partial_{x}\left(g \left[k_{x} \partial_{x}\left(\underline{\rho}+\rho_{v}\right)(z-)\right.\right.}
\end{array}
$$

The first term $t_{0}$ is the time variation of $\phi$ (De Boer et al., 2008, eq. 6). The term $t_{1}$ represents the horizontal advection of the longitudinal density difference in relation to the average density. The term $t_{A}$ is the longitudinal advection of the potential energy anomaly as defined by Simpson (1981), $\phi_{S}$ (eq. (1)), due to the vertical average of the longitudinal velocity; $t_{B}$ is the depth-mean straining, based on the vertical mean horizontal density gradient strained by the deviation from the depth-mean velocity vector (Bowden, 1981), also called the differential advection term by van Aken (1986) (see also Burchard and Hofmeister (2008)); $t_{C}$ is the non-averaged differential advection based on the deviations of the longitudinal velocities and the gradient of the density deviations. As for the potential energy anomaly, $t_{B}$ and $t_{C}$ include velocity deviations $u_{v}$ and their longitudinal gradients. The term $t_{D}$ is the vertical advection due to the deviations in regard to the vertical average of the vertical velocity. The term $t_{E}$ is an estimation of the turbulent flux of density that depends on the eddy diffusivity coefficient (van Aken, 1986; Simpson \& Bowers, 1981; Simpson \& Sharples, 2012). The surface and bottom bouyancy transports are included in the term $t_{F}$. The source and sink terms related to heat transport on the free surface $\left(R=\left(1-e^{-k d}\right) \underline{z}+\left[\varepsilon^{-1}-e^{-k d}\left(d+\varepsilon^{-1}\right)\right]\right.$, (first term) and the bed sediment resuspension (second term) are indicated in $t_{G}$. Finally, the mean turbulent transport divergence throughout the estuary is defined by $t_{H}$ whereas $t_{I}$ is the divergence of the mean turbulent transport through the boundaries $z=\eta$ and $z=-h$. To facilitate their tracking, these terms were renamed as follows: $\Psi_{\zeta}=g d^{-1}(\underline{z}-\zeta)\left[k_{x} \partial_{x}(\underline{\rho}+\right.$ $\left.\left.\rho_{v}\right)\right]_{\zeta} \partial_{x} \zeta$ for $\zeta=\eta,-h$.

\subsubsection{Application to weakly stratified estuaries}

In weakly stratified or well-mixed estuaries, the vertical density profile is practically constant, i.e. $\rho_{v} \simeq \rho_{0, v} \simeq 0$. The term $t_{E}$ cannot be neglected since it is the mechanism that sustains mixing in the water column and determines the vertical mass exchange in weakly stratified estuaries (Jay \& Smith, 1990). Assuming this hypothesis, eq. (8) is simplified as follows:

$$
\begin{array}{r}
\partial_{t} \phi+g \partial_{x}\left(\left(\underline{\rho_{0}}-\underline{\rho}\right) \underline{u} \underline{z}\right) \\
-g \partial_{x}\left(\underline{\rho} \underline{u_{v} z}\right)-g \underline{k_{z} \partial_{z} \rho}-\frac{g \rho \alpha_{w}}{\rho_{0} c_{p}} R+\Psi_{\eta}-\Psi_{-h}=0 .
\end{array}
$$

In the case of other estuaries, different hypotheses can be adopted that simplify the general equation (eq. (8)).

\subsection{Box model of the LAPE}

The following section describes how the estuary was divided into a series of interconnected boxes that are representative of the subtidal-scale flow characteristics. For a box $i$ (figure 1), eq. (9) is integrated with respect to a $x$ between two sections, $x_{i}$ and 
$x_{i}+L_{i}$. When the tidal decomposition of the resulting variables is substituted, this gives the LAPE equation for the box at the subtidal scale:

$$
\begin{array}{r}
\underbrace{\Delta_{t} \bar{\Phi}}_{\tau_{0}}+ \\
+\underbrace{\frac{g B}{2} \Delta_{x} F_{2}\left(d, \underline{\rho_{0}}-\underline{\rho}, \underline{u}\right)}_{\tau_{1}}-\underbrace{g B \Delta_{x} F_{1}\left(\underline{\rho}, \underline{\left.u_{v} z\right)}\right.}_{\tau_{2}} \\
+\underbrace{\frac{4 \epsilon}{3 \pi} \frac{C_{d} \rho \bar{u}^{3} A_{s}}{h}+\frac{\delta k_{s} \rho_{a} \bar{W}^{3} A_{s}}{h}-}_{\tau_{3}}-\underbrace{\frac{g \rho \alpha_{w}}{\rho_{0} c_{p}} A_{s} \bar{R}}_{\tau_{5}} \\
+\underbrace{\overline{\left\langle\Psi_{\eta}\right\rangle}}_{\tau_{4}}-\overline{\left\langle\Psi_{-h}\right\rangle}=0,
\end{array}
$$

where for a generic variable $\zeta,\langle\zeta\rangle=\int_{x_{i}}^{x_{i}+L_{i}} \zeta d x$ is the integral in the length of a box, $L_{i}$; and, $\bar{\zeta}=T_{M_{2}}^{-1} \int_{t}^{t+T_{M_{2}}} \zeta d t$ is the time average in a tidal cycle $T_{M_{2}}$, which permits the decomposition of $\zeta=\bar{\zeta}+\zeta^{\prime}$, where $\zeta^{\prime}$ is the deviation in regard to the average. At the same time, $\Delta_{t} \zeta$ represents the time difference of $\zeta$ evaluated in $t$ and $t+T_{M_{2}}$; and $\Delta_{x} \zeta$ represents the spatial difference of $\zeta$ evaluated in $x$ and $x+L$. The functions $F_{1}$ and $F_{2}$ are given by:

$$
F_{2}\left(\zeta_{1}, \zeta_{2}, \zeta_{3}\right)=\overline{\zeta_{1}} \overline{\zeta_{2}} \overline{\zeta_{3}}+\overline{\zeta_{1}} \overline{\zeta_{2}^{\prime} \zeta_{3}^{\prime}}+\overline{\zeta_{2}} \overline{\zeta_{1}^{\prime}\left(\zeta_{1}, \zeta_{2}\right)}+\overline{\zeta_{3}} \overline{\zeta_{1}^{\prime} \zeta_{2}^{\prime}} \overline{\zeta_{2}}+\overline{\zeta_{1}^{\prime} \zeta_{2}^{\prime} \zeta_{2}^{\prime}}
$$

a. Sketch of estuarine model

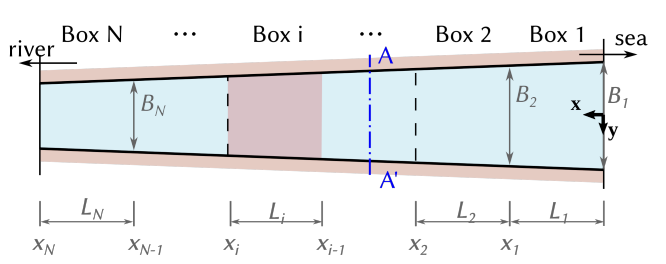

b. Cross-sectional geometry Section $A-A^{\prime}$

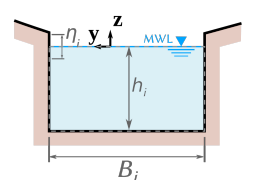

Figure 1. Diagram of the estuary box model and reference frame. a) Global diagram of the estuarine model. The red-shaded region stands for the surface area of box- $\left.i, A_{s, i} ; b\right)$ geometry of the cross-section. The gray dashed rectangle is the geometry of the box cross-section, $A_{i}$.

In eq. (10), $\Phi=\int_{A_{s}} \phi d A\left(\mathrm{~J} \cdot \mathrm{m}^{-1}\right)$ represents the LAPE of the box. The term $\tau_{0}$ is the variation experienced by $\Phi$ from the beginning to the end of the tidal cycle. The term $\tau_{1}$ includes the superposition of the mean transport $\left[\tau_{1,1}=h \underline{\bar{u}} \overline{\left(\rho_{0}-\rho\right)}\right]$, the Stokes transport $\left[\tau_{1,2}=\overline{\left(\rho_{0}-\underline{\rho}\right)} \overline{\eta \underline{u^{\prime}}}\right]$, and three tidal pumpings related to correlations between $\eta+h, u^{\prime}$ and $\left(\underline{\rho_{0}}-\underline{\rho}\right)^{\prime}\left[\tau_{1,3}=\underline{\bar{u}} \overline{\eta\left(\underline{\rho_{0}}-\underline{\rho}\right)^{\prime}} ; \tau_{1,4}=h \underline{\underline{u^{\prime}} \underline{\left(\rho_{0}-\underline{\rho}\right)^{\prime}} ;} \tau_{1,5}=\overline{\eta \underline{u^{\prime}}\left(\underline{\rho_{0}}-\underline{\rho}\right)^{\prime}}\right]$. The term $\tau_{2}$ considers the depth-averaged advection density, spatiotemporal depth changes, and mean vertical mass transports. The term $\tau_{3}$, which is obtained from $\left(t_{E}\right)$ in eq. (8), is empirically related to tidal and wind mixing (van Aken, 1986; Simpson, 1981). According to Simpson (1981); Simpson and Bowers (1981); Simpson et al. (1991), the mixing term is described by the cube of the tidal velocity $\bar{u}$ and the wind velocity $\bar{W}$. The constant parameters $\epsilon, \delta, C_{d}$ and $k_{s}$ represent the effective surface drag force, bottom drag force, tidal current mixing, and wind mixing, respectively. The term $\rho_{a}$ denotes the air density at sea level. The surface solar radiation is $\tau_{4}$. Finally, $\tau_{5}$ describes the turbulent 
horizontal transport difference between $z=\eta$ and $z=-h$. The LAPE transports due to tidal pumping $\left(\tau_{1,4}\right)$, differential advection $\left(\tau_{2}\right)$ and longitudinal dispersion $\left(\tau_{5}\right)$ were not contemplated by (Garvine \& Whitney, 2006) in their box model.

In what follows, all variables are averaged in a tide cycle, although for the sake of simplicity, the lower bar in the equations indicating this has been eliminated.

\section{Application to the Guadalquivir River Estuary}

\subsection{Study zone}

The Guadalquivir River Estuary (GRE) is located in the southeast of Spain $\left(36^{\circ} 43^{\prime} \mathrm{N}\right.$ $\left.-37^{\circ} 32^{\prime} \mathrm{N}, 5^{\circ} 56^{\prime} \mathrm{W}-6^{\circ} 30^{\prime} \mathrm{W}\right)$. It is a transition zone between the river basin of the same name and the Gulf of Cadiz (figure 2). The estuary comprises the last $110 \mathrm{~km}, 85$ of which are navigable as far as Seville. The Alcalá del Río dam is the upstream tidal limit. The estuary is weakly convergent: channel widths vary from $800 \mathrm{~m}$ near the mouth to $150 \mathrm{~m}$ at the head. The channel mean depth is approximately equal to 7 meters, artificially maintained in many stretches by dredging to favor navigation.

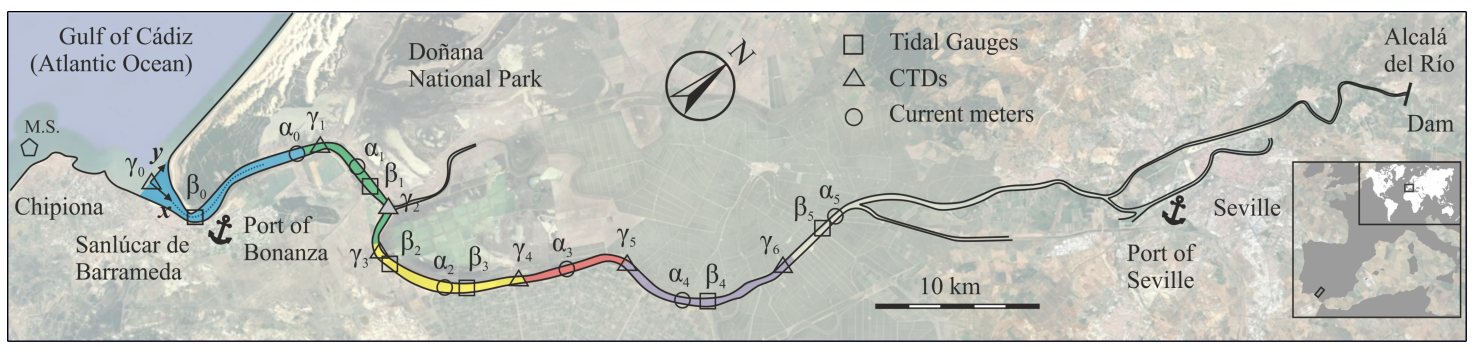

Figure 2. Map of study area with the location of the monitoring network stations (Navarro et al., 2011). The monitoring network is composed of current-meter profilers (ADCPs), tidal gauges, a meteorological station (M.S.) and environmental quality probes or CTDs. The origin of the along-channel coordinate $\left(\mathrm{km} 0\right.$ at $\left.\gamma_{0}\right)$ was established at the mouth and follows the thalweg. Colored stretches designate the extension of the boxes in the model (see Table 1). This color code is the same throughout the manuscript.

The GRE is a positive estuary, dominated by the flood tide and mesotidal range (tidal range of $<4 \mathrm{~m}$ at the mouth), where the most significant tidal constituents are $M_{2}$, $S_{2}$, and $N_{2}$. The GRE is generally dominated by tidal processes and is weakly stratified when fluvial discharges are not greater than $40 \mathrm{~m}^{3} \mathrm{~s}^{-1}$, which occurs over $75 \%$ of the year (Díez-Minguito et al., 2012). Mean density deviations from the vertical density average are less than $1.42 \mathrm{~kg} \cdot \mathrm{m}^{-3}$. The estuary number is less than 0.05 ; the densimetric Froude number is smaller than 0.014; and the Richardson number of the estuary is less than 0.3 (Díez-Minguito et al., 2013).

\subsection{Data collection}

The data for the study were collected in real time from 2008 until 2010 with a remote monitoring system installed by the Institute of Marine Sciences of Andalusia (ICMANCSIC) (Navarro et al., 2011). Figure 2 shows the instrumentation at the estuary, namely, six environmental-quality monitoring stations, six water level sensors, six acoustic Doppler velocimeters, and a meteorological station, represented by $\alpha, \beta, \gamma$, and M.S., respectively. The environmental quality station recorded temperature $(T)$, salinity $(S)$, and suspended solids concentration every thirty minutes at four different depths $(z=-1,-2,-3$ and $-4 \mathrm{~m})$. 
These data were used to calculate the fluid density $\rho(S, T, C, p)$ (sea water and suspended sediment mixture) as $\rho=\rho_{w}+\left(1-\rho_{w} / \rho_{s}\right) C$, in which the water density, $\rho_{w}(S, T, p)$ was obtained from the equation of state for seawater. The sediment density, $\rho_{s}$, was considered to be equal to $2650 \mathrm{~kg} \cdot \mathrm{m}^{-3}$ (Díez-Minguito et al., 2014). Water level sensors recorded the position of the free water surface every 10 minutes, and these data were used to calculate the tidal range. Current data were measured every 15 minutes by means of acoustic current profilers. At the head of the estuary, daily data pertaining to the discharges from the Alcalá del Río dam were obtained from the Regional Water Management Agency (Agencia Andaluza del Agua, Junta de Andalucía). Wind velocity and direction and solar radiation were measured every 10 minutes in the meteorological station at the mouth of the GRE.

\subsection{Configuration of the model}

The previously described LAPE formulation was applied to the GRE from 07/24/2008 to $07 / 24 / 2009$. Figure $3 . f$ shows the following hydraulic regimes that were observed during this one-year period (Díez-Minguito et al., 2012): (1) low-river flow; (2) high-river flow; and (3) an intermediate riverflood recovery period. These regimes are discussed at length in the sections that follow.

The spatial domain extended from the mouth, $x=0 \mathrm{~km}$, to $x=57.6 \mathrm{~km}$ upstream, the average position reached by the 2-psu isohaline (Monismith et al., 2002), which characterizes salt intrusion. The upper stretch of the estuary, which normally has the characteristics of a tidal river, was not considered. The GRE was divided into five boxes, whose length, width, and depth are defined in Table 1. These boxes are representative of estuarine dynamics regarding tidal wave propagation, salt transport, and suspended particulate material transport along the GRE.

Equation (3) was used to calculate $\phi$ in the five boxes, using the data observed (figure 3 ). In each box, the reference density, $\rho_{0, i}$, is the density at the point farthest downstream; $\rho_{i}$ is the density at the point farthest upstream; and $h_{i}$ is the average depth for $i=1,2, \ldots, 5$. Typical average density values at these points are also shown in Table 1 . The equation (10) evaluates the transports that control the LAPE, which are derived in Section 2.2.1, also based on the data observed.

In order to compare the results of our study with those of the seminal work of Garvine and Whitney (2006) in the Delaware estuary, the average LAPE was also calculated throughout the study zone, $\phi_{e}$, as though it were a single box. This was obtained with the following expression:

$$
\phi_{e}=A_{s, t}^{-1} \sum_{i=1}^{N} \phi_{i} A_{s, i} \quad i=1,2, \ldots, 5,
$$

where $A_{s, t}=\sum_{1}^{5} A_{s, i}$, the total surface area of the study zone. In the same way, the net transport of the estuary was calculated for a term $j$, as follows:

$$
\tau_{e, j}=A_{s, t}^{-1} \sum_{i=1}^{N} \tau_{j, i} A_{s, i} \quad i=1,2, \ldots, 5 .
$$

\section{Results}

\subsection{Observational background}

This section analyzes the observations in order to ascertain the influence of the suspended solids concentration, water temperature, and salinity on water density for the different fluvial regimes during the study period. This analysis clarifies the interpretation of the spatiotemporal variability of the LAPE. In figure 3, panels (a), (b), (c) and 
Table 1. Morphological parameters of the boxes used in the subtidal box model. Each box is defined by its initial downstream position $x_{i}$; its final upstream position $x_{i+1}$, length $L_{i}$; and the limiting cross-sections of areas $A_{i+1}$ and $A_{i}$ (figure 1). The surface area of each box is defined by $A_{s, i}$. Also shown are typical vertical averaged density values and their deviations in regard to the vertical average value, $\rho_{v}$, in each box. Besides the density values, the percentiles 5 and 95 of the time-series of density deviations are shown in brackets.

\begin{tabular}{cc|ccccc|cc}
\hline & \multicolumn{2}{c}{ Box } & \multicolumn{9}{c}{$\begin{array}{c}\text { Geometry } \\
\text { no. }\end{array}$} & Color & $\begin{array}{c}\mathbf{x}_{\mathbf{i}} \\
(\mathbf{k m})\end{array}$ & $\begin{array}{c}\mathbf{L}_{\mathbf{i}} \\
\mathbf{( k m})\end{array}$ & $\begin{array}{c}\mathbf{h}_{\mathbf{i}} \\
(\mathbf{m})\end{array}$ & $\begin{array}{c}\mathbf{A}_{\mathbf{i}} \\
\left(\mathbf{1 0}^{\mathbf{2}} \mathbf{m}^{\mathbf{2}}\right)\end{array}$ & $\begin{array}{c}\mathbf{A}_{\mathbf{s}, \mathbf{i}} \\
\left(\mathbf{1 0}^{\mathbf{6}} \mathbf{m}^{\mathbf{2}}\right)\end{array}$ & $\begin{array}{c}\bar{\rho}(5 \%, 95 \%) \\
\mathbf{k g} \cdot \mathbf{m}^{-\mathbf{3}}\end{array}$ & $\begin{array}{c}\text { Density variability } \\
\rho_{\mathbf{v}}(5 \%, 95 \%) \\
\mathbf{k g} \cdot \mathbf{m}^{-\mathbf{3}}\end{array}$ \\
\hline 1 & cyan & 0 & 17.3 & 7.26 & 58.39 & 12.91 & $1023.75(-4.30,3.12)$ & $0.41(-0.31,0.60)$ \\
2 & green & 17.3 & 8.9 & 7.13 & 43.82 & 5.22 & $1012.64(-7.01,6.82)$ & $0.21(-0.04,0.24)$ \\
3 & orange & 26.2 & 9.1 & 7.05 & 37.80 & 4.54 & $1007.01(-4.48,4.70)$ & $0.11(-0.11,0.44)$ \\
4 & red & 35.3 & 11.8 & 6.95 & 32.51 & 4.90 & $1004.22(-3.12,5.31)$ & $1.42(-1.20,0.50)$ \\
5 & purple & 47.1 & 10.5 & 6.85 & 26.72 & 3.56 & $1001.67(-1.99,3.31)$ & $0.07(-0.05,0.24)$ \\
- & - & 57.6 & - & 6.80 & 22.45 & - & $1000.97(-2.54,3.37)$ & $0.25(-0.14,0.20)$ \\
\hline
\end{tabular}

(d) show, respectively, the tidal-averaged time series of the vertically-averaged suspended solids concentration, salinity, water temperature, and density for different locations in the estuary (colored curves). Panel (e) shows the tidal range at the estuary mouth, and panel (f), the fluvial discharge during the study period.

During the summer of 2008 (1), the estuary remained in a low-river flow regime with fluvial discharges of less than $40 \mathrm{~m}^{3} \mathrm{~s}^{-1}$. In these conditions, tidal currents determine estuarine dynamics. The suspended particulate material throughout the estuary scarcely reached $2 \mathrm{~kg} \cdot \mathrm{m}^{-3}$ during the summer. In autumn and the beginning of the winter in that same year, pulsed discharges reached $100 \mathrm{~m}^{3} \mathrm{~s}^{-1}$ and lasted for various days (blue arrows in figure 3.f). This produced a marked decrease in salinity and density $(\Delta \rho \simeq$ $\left.5 \mathrm{~kg} / \mathrm{m}^{3}\right)$.

In the middle of winter (2), intense rains made it necessary to open the floodgates of the dam upstream. The discharge reached the threshold of extreme fluvial conditions in the $\operatorname{GRE}\left(Q>400 \mathrm{~m}^{3} \mathrm{~s}^{-1}\right)$. Density dropped sharply to freshwater levels in the entire estuary, except at the mouth, where the density reduction was $15 \mathrm{~kg} / \mathrm{m}^{3}$. The fluvial discharge caused the salt to be transported seaward from the estuary. It also increased the quantity of sediments suspended from the bed, which led to a turbidity peak approaching $10 \mathrm{~kg} \cdot \mathrm{m}^{-3}$ (fig. 3.a). During this period, the mouth showed the maximum horizontal density gradient of the estuary.

This episode was followed by a recovery period (3) in which the fluvial discharge of the dam again decreased with values below the threshold of $40 \mathrm{~m}^{3} \mathrm{~s}^{-1}$. The salt that had been transported towards the mouth by the discharge began to move upstream again (figure 3.b). These conditions persisted until the beginning of the summer of 2009, when salinity levels and the sediment concentration were once more typical of low river flows. The summer was characterized by a slight linear reduction in density detected by all sensors. This was caused by the increase in water temperatures because of short-wave radiation (Padilla et al., 2016). 

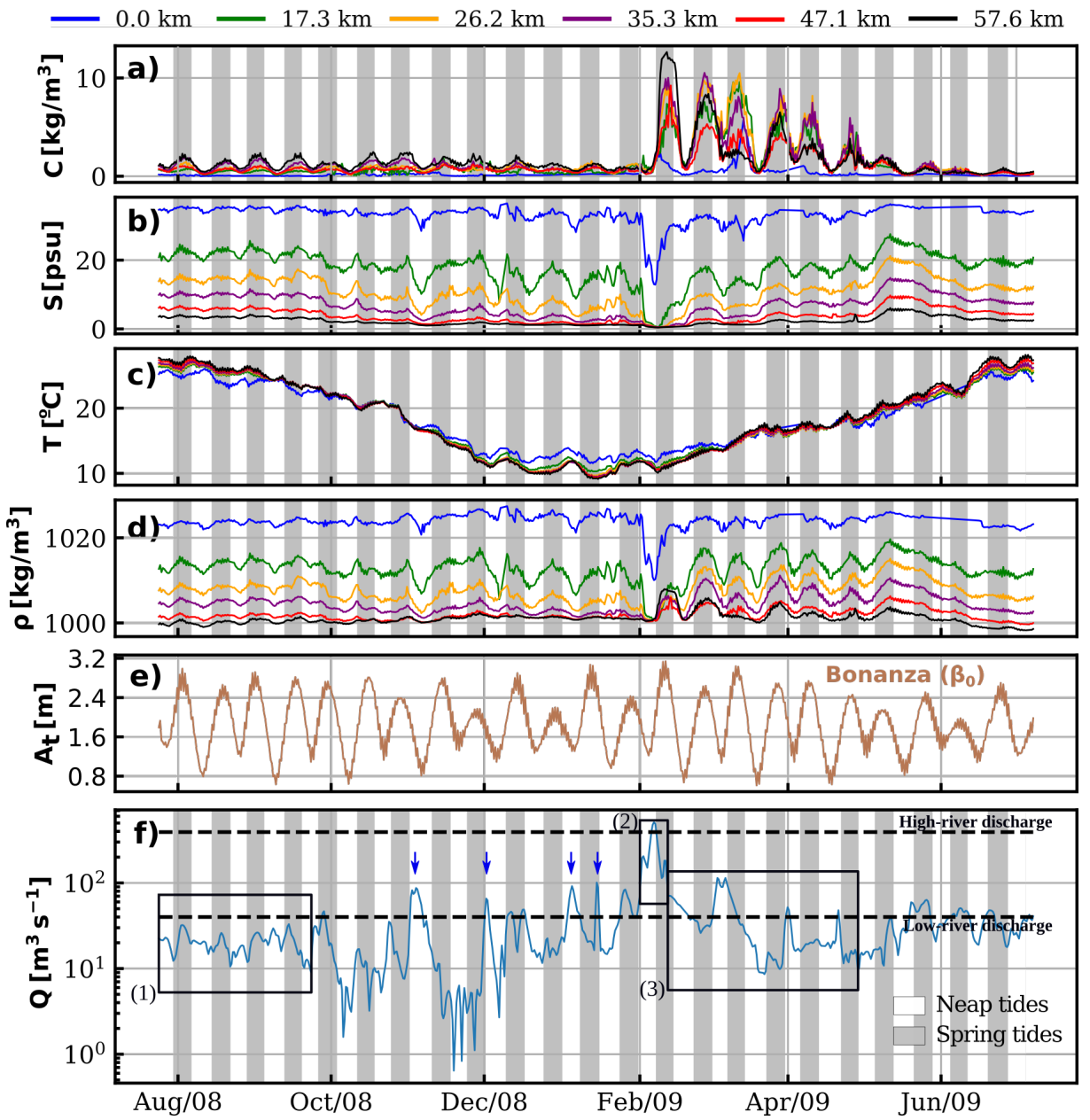

Figure 3. Time series of the tidal-averaged a) vertically-averaged concentration of suspended particulate material; b) vertically-averaged salinity; c) vertically-averaged temperature; $d$ ) vertically-averaged density; e) tidal range at Port of Bonanza; and, $f$ ) daily river discharges from the Alcalá del Río dam during the study period. Several boxes are displayed in panel $f$ ): (1) refers to the low-river flow regime; (2) refers to the high-river flow regime; and (3) stands for the recovery period. Spring and neap periods are also displayed. Blue arrows indicate pulsed discharges lasting various days, reaching $100 \mathrm{~m}^{3} \mathrm{~s}^{-1}$, which were not normal conditions for the estuary.

\subsection{Evaluation of the LAPE}

\subsubsection{Longitudinal variation of $\phi(x)$}

Figure 4.a shows the results of eq. (3) at several sections representative of the conditions at the boxes defined in Table 1 , where $\phi_{i}$ indicates the longitudinal anomaly of the potential energy (LAPE or $\phi$ ) at $x_{i}$. The first third of the estuary (boxes 1 and 2 ) shows the highest values of $\phi$, where the maximum average longitudinal density gradients occur as well as the greatest time variability. The LAPE for box 1 during the study period is $\phi_{1}=395.04 \pm 122.68 \mathrm{Jm}^{-3}$, where the first term is the mean value and $\pm X$ is the standard deviation. The amplitude of the fortnightly modulation of $\phi_{i}$ and its mean value decrease upstream $\left(\phi_{5} \simeq 90 \pm 45 \mathrm{Jm}^{-3}\right)$. In box $1, \phi$ oscillates out of phase with the fortnightly constituent of the tidal range with minimums of $\phi$ during spring tides and 
maximums during neap tides. Upstream, just the opposite occurs. The reason of the fortnightly change of $\phi$ will be discussed in the next section. The dependence of $\phi$ on the neap-spring-tide cycles was no longer visible from October 2008 until February 2009 because the intermediate fluvial pulsed discharges became more numerous $\left(\simeq 100 \mathrm{~m}^{3} / \mathrm{s}\right)($ figure 4.d). The 2-psu isohaline (figure 4.c) reaches box 5, where $\phi_{i}$ remains almost constant during low riverflow conditions. However, it retreats to $x=40 \mathrm{~km}$ with the pulsed discharges observed at the end of autumn which is manifested in a reduction of $\phi$ in boxes 4 and 5. Then, it moves to box 1 during the flood (2), causing a marked decrease in $\phi$ in all boxes. On a yearly scale, at the mouth, positive temperature increases generated negative increases in $\phi$. Upstream, the temperature oscillation is in phase with $\phi$.

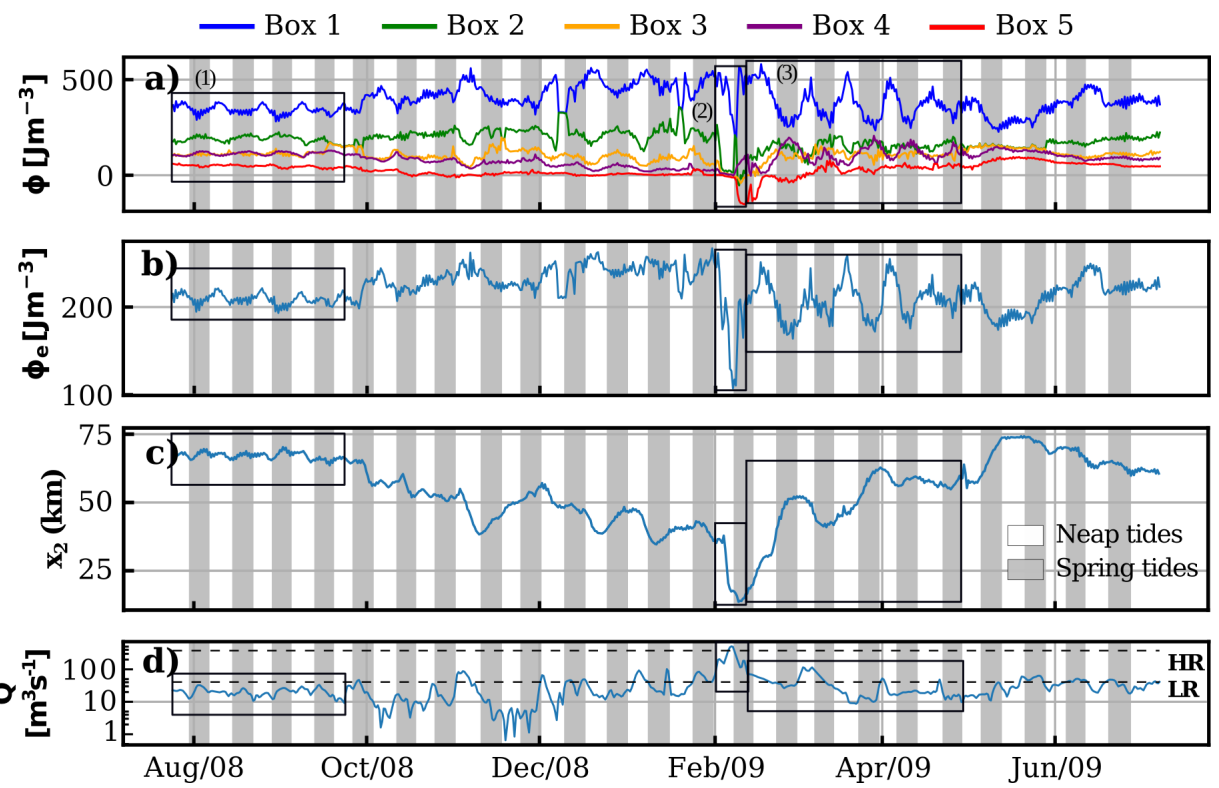

Figure 4. Time series of the longitudinal potential energy anomaly. a) $\phi_{i}$ at every box; b) $\phi_{e}$ of the estuary (eq. (12)); c) salt intrusion during the study period (2-psu isohaline from figure 8 of Díez-Minguito et al. (2013)); and, d) daily river discharges from the Alcalá del Río dam during the study period. HR and LR indicate high-river flow and low-river flow regime. Boxes represent the periods discussed in the main text.

Generally, the value of $\phi_{e}$ remains more or less constant in low-river flow conditions (1), which is to be expected because of the small time variations in the density observed at the estuary mouth and head (figure 3.d). During the high-river flow regime (2), $\phi_{e}$ decreases by half because of the seaward movement of the salt intrusion. The dependence of the salt intrusion increases with the freshwater flow (Reyes-Merlo et al., 2013). The salt intrusion during (2) moves upstream to kilometer 15. During the subsequent recovery period (3), $\phi_{e}$ oscillates out of phase $\pi$ with the tides. The mean value and variability of $\phi_{e} \simeq 218.82 \pm 36.89 \mathrm{Jm}^{-3}$ are in accordance with the values obtained by Garvine and Whitney (2006) in the Delaware estuary where the mean estuary depth is $8 \mathrm{~m}$. The amplitude of the oscillation triples during the recovery period ranging from a little more than $15 \mathrm{Jm}^{-3}$, corresponding to what is observed in normal conditions, to almost $50 \mathrm{Jm}^{-3}$, mostly conditioned by the box of the estuary mouth. 


\subsubsection{Variation of $\phi(x)$ depending on fluvial regime}

Figure 5 shows the profiles of $\rho(x)$ and $\phi(x)$ for the different regimes (low-river flow, high-river flow, and post-riverflood recovery). In all cases, it was observed that the variability in regard to that mean density profile (orange line, figure 5) decreases upstream.

In normal conditions (1) (fig. 5.a), the mean density in each box decreases from the mouth upstream. This decrease is linear to $\mathrm{km} \mathrm{40.} \mathrm{The} \mathrm{LAPE} \mathrm{decreases} \mathrm{more} \mathrm{gradu-}$ ally upstream. During the high-river flow regime (2) (figure 5.b), almost the entire estuary is composed of freshwater, which gives values of $\phi \simeq 0$ except for the mouth. In boxes 3 and $5, \phi$ is negative, which means that the density is locally inverted $\left(\rho_{3}>\rho_{2}\right.$ and $\left.\rho_{5}>\rho_{4}\right)$.
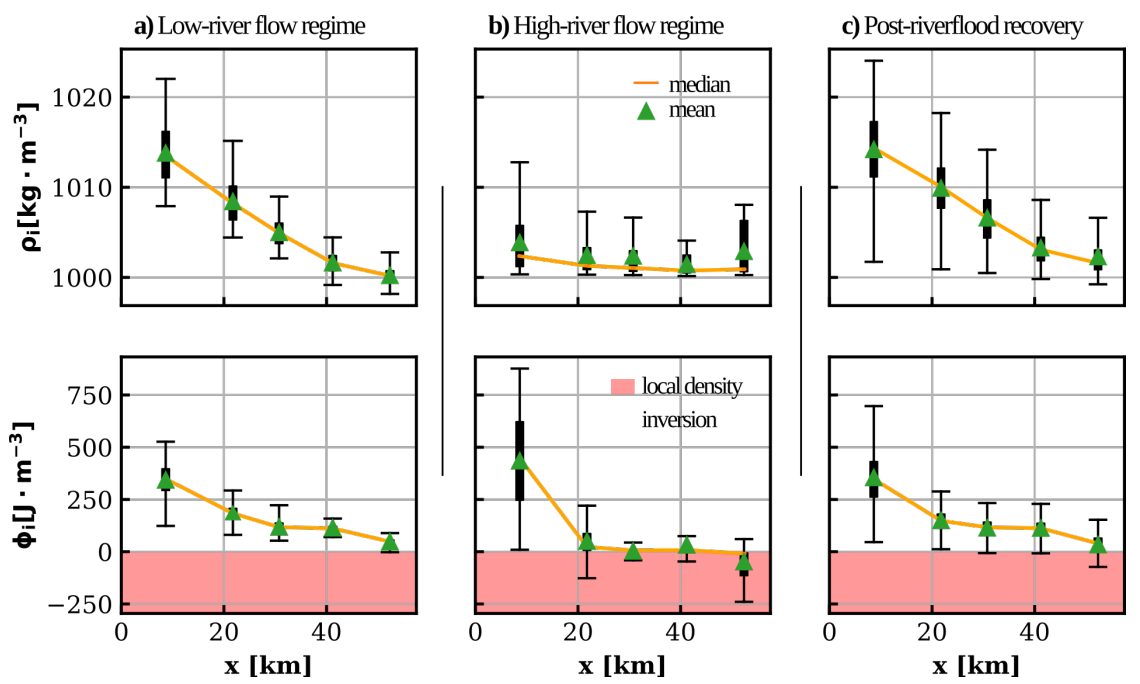

Figure 5. Along-channel density and longitudinal anomaly of potential energy for different regimes: a) low-river flow; b) high-river flow; and, c) post-riverflood recovery period. The rectangle in error bars indicate the corresponding \pm 1 quartile from the median whereas line edges indicate 5 and 95 percentiles. Shaded areas indicate local density inversion $\rho_{i}>\rho_{i-1}$.

In the recovery period (3), the along-channel density (fig. 5.c, upper panel) shows a similar profile to that observed in normal conditions, where the variability in $\rho(x)$ as well as $\phi(x)$ is maximum during recovery. The negative values of $\phi$ persist until the density observed in normal conditions is recovered because the values approach the estuarine turbidity maximum (ETM) (Díez-Minguito et al., 2014).

\subsection{Evaluation of LAPE transports}

\subsubsection{Longitudinal variation of advective transports of $\phi$}

Figure 6 shows the main advective transport terms in each box, calculated in accordance with equation (10). Terms $\tau_{1,1}, \tau_{1,2}$ and $\tau_{1,4}$ represent the average non-tidal advective $\phi$-transport, the LAPE transport due to Stokes and the tidal pumping $\phi$-transport induced by the correlation between currents and densities. These terms represent more than $99 \%$ of the advective transport of $\phi$. The terms $\tau_{1,3}$ and $\tau_{1,5}$ are not shown since they are various orders of magnitude lower than the latter ones $\left(\simeq 10^{2} \mathrm{Wm}^{-1}\right)$. At the estuary mouth, the mean non-tidal advective LAPE transport, $\tau_{1,1}$, is negative $\simeq-1.5$ $\cdot 10^{4} \mathrm{Wm}^{-1}$ (blue curve in fig. 6.a), which indicates that the non-tidal residual currents flow seaward. Upstream, this mean value becomes positive (green curve), then negative 

also observed in Stokes-induced and tidal pumping transport processes.
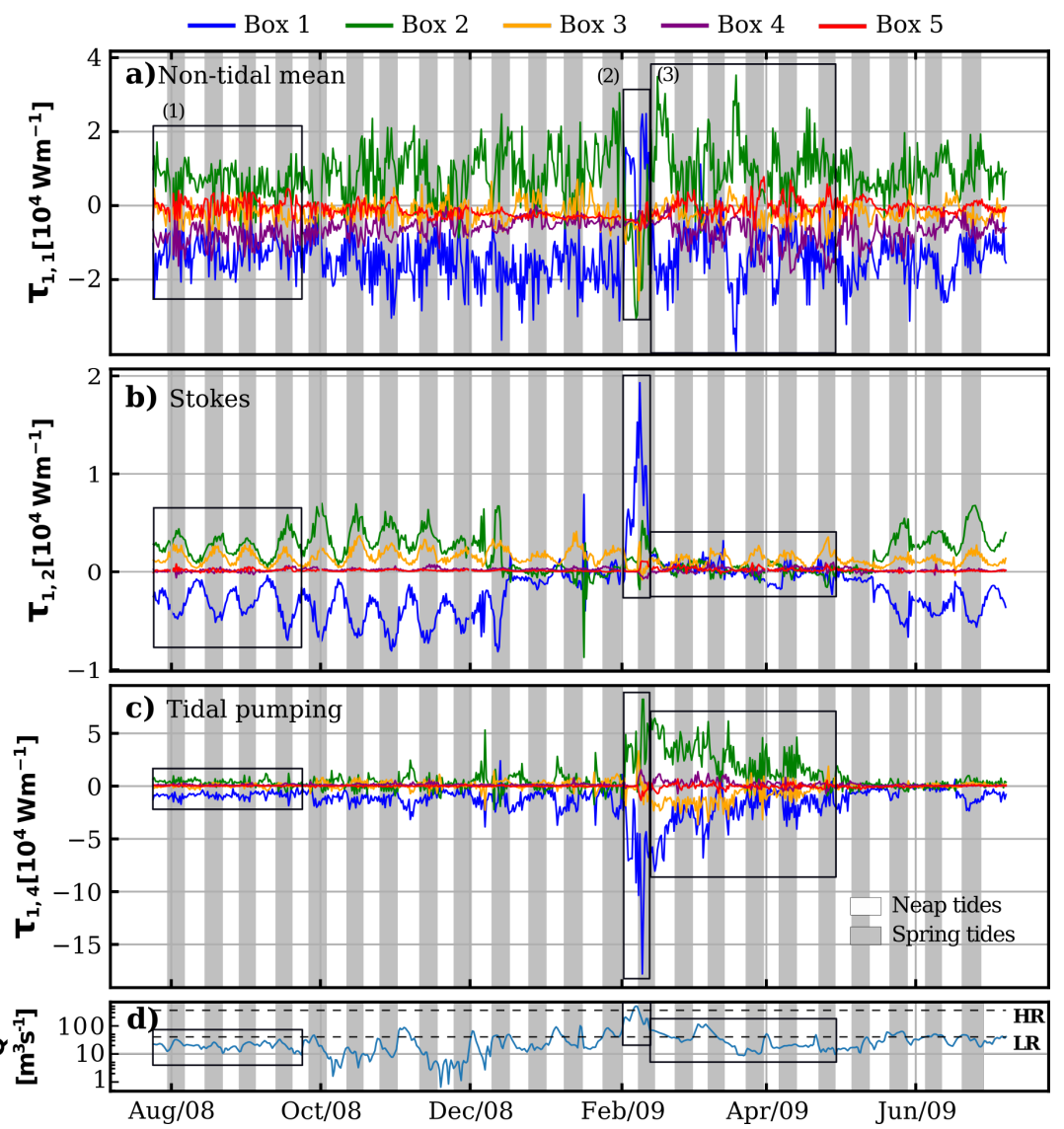

Figure 6. Time series of the most significant advective terms of the LAPE along the estuary. a) Non-tidal mean; b) Stokes; c) tidal pumping due to the correlation between currents, elevations and densities; and, d) daily river discharges from the Alcalá del Río dam over the study period. HR and LR indicate the high-river and low-river flow regime, respectively. Positive values are upstream. Boxes represent the periods discussed in the main text.

During the low-river flow regime $(1), \phi$-transports due to Stokes $\left(\tau_{1,2}\right)$ and tidal pumping $\left(\tau_{1,4}\right)$ are in phase with the tidal range. At the estuary mouth, the dependence of $\tau_{1,1}$ on the tidal range is not as clear. The term, $\tau_{1,1}$ has a greater magnitude than $\tau_{1,4}$ and $\tau_{1,2}$. More specifically, $\tau_{1,2}$ is approximately one-fourth of $\tau_{1,1}$.

The non-tidal mean advective $\phi$-transport and tidal pumping are primarily responsible for the fortnightly change in density during the low-river flow $\left(\simeq 2 \cdot 10^{4} \mathrm{Wm}^{-1}\right.$, in absolute value). Transport magnitude decreases upstream except in box 3 where it increases. Upstream transports (box 4 and 5) become negligible.

In the high-river flow regime (2), $\tau_{1,1}$ is inverted and the transport in boxes 2 and 3 drops to $\simeq-2.5 \cdot 10^{4} \mathrm{Wm}^{-1}$, whose absolute value exceeds that of the first box. Nontidal mean advective and Stokes $\phi$-transports at the estuary mouth are in the upstream direction in contrast to what occurs in the following box. The $\tau_{1,2}$ and $\tau_{1,4}$ transports intensify with the discharge. This means that tidal pumping $\left(\tau_{1,4}\right)$ is now the dominant 
process in the first third of the estuary, moving seaward at the mouth $\left(\simeq-15 \cdot 10^{4} \mathrm{Wm}^{-1}\right)$ and upstream in the following box $\left(\simeq 5 \cdot 10^{4} \mathrm{Wm}^{-1}\right)$.

During the recovery period (3), the mean transport regains its values in low-river flow conditions and when it is in phase with the tide. The Stokes-induced LAPE transport $\left(\tau_{1,2}\right)$ recovers the values observed in (1). In the case of tidal pumping, maximums observed during the discharge progressively attenuated until the total recovery of the estuary in May 2009.

\subsubsection{Longitudinal variability of $\phi$-transports for different fluvial regimes}

This section jointly analyzes, in terms of LAPE transport, the longitudinal variability of the dominant processes observed in the GRE during periods of neap and spring tides in normal conditions, recovery conditions, and during the high-river flow regime. Figure 7 shows the median values $(\hat{\tau})$ of the LAPE transport results.
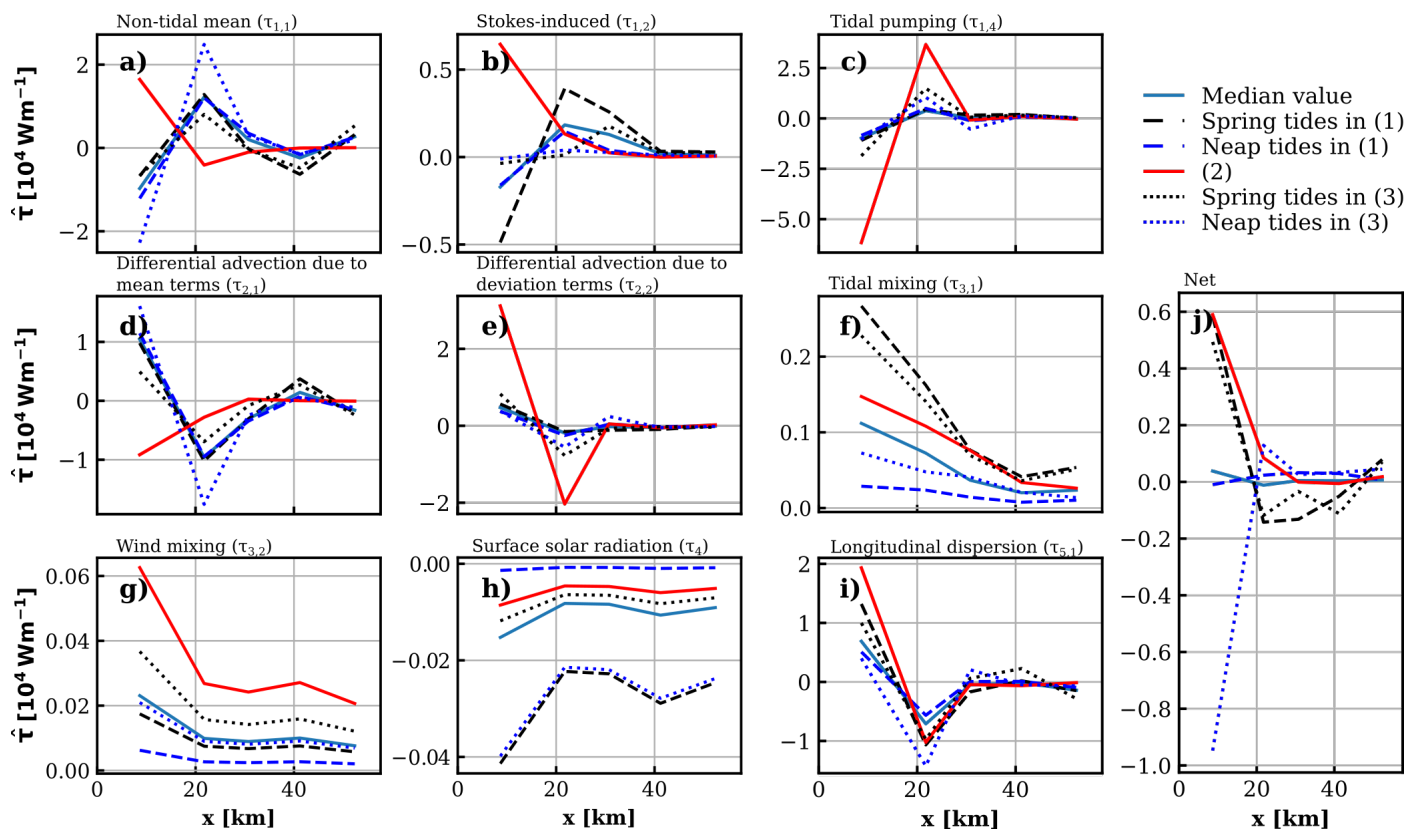

Figure 7. Median values of several LAPE transports along the estuary under different flow conditions. Panel $j$ ) shows the sum of terms a) to $i$ ). Low-river flow, high-river flow and recovery periods are indicated as (1), (2), and (3), respectively. Positive values are upstream.

During (1), non-tidal mean, Stokes-induced, and tidal pumping $\phi$-transports at the mouth are seaward. This behavior is inverted upstream $(x=26.2 \mathrm{~km})$, where the value is of the same order, but positive. From here upstream, these $\phi$-transports decrease and show a negative value in $x=47.5 \mathrm{~km}$. This variability causes various points of energy transport convergence and divergence to appear throughout the estuary. More specifically, near kilometer 15 , there is a divergence point of $\tau_{1,1}, \tau_{1,2}$ and $\tau_{1,4}$. Near $x=35 \mathrm{~km}$, another convergence point for the same transports is also identified. In spring tides, the mean LAPE transport value is greater near the mouth and decreases after the divergence point. The term $\tau_{1,1}$ varies considerably along the estuary, due to phase changes between the longitudinal velocity and density. Although the longitudinal transport profile intensifies during spring tides in the estuary recovery period, in neap tides, this same value visibly decreases in $x=17.3 \mathrm{~km}$. It is important to highlight how the longitudinal profile of $\tau_{1,1}$ is inverted during the fluvial discharge (2). Moreover, as can be observed the 
net LAPE transport in spring tides (fig. 7.j) is positive at the mouth and negative, upstream, whereas in neap tides, it is practically zero in the entire estuary.

The Stokes-induced $\phi$-transport (fig. 7.b) shows a similar pattern during flow conditions (1) and (2) except for the fact that it becomes practically negligible upstream from the divergence point and during the recovery phase. In any case, the Stokes-induced $\phi$-transport has a magnitude that is slightly less than that obtained for the non-tidal mean advection. The upstream decrease in the Stokes-associated $\phi$-transport is also controlled by the phase lag between elevations and tidal currents. This phase lag approached $\pi / 2$ upstream because of the partial standing nature of tidal wave propagation due to the tide reflection in the dam at the head of the estuary (Díez-Minguito et al., 2012). Tidal pumping $\tau_{1,4}$ (figure 7.c) also has the same profile with the absolute maximum value of its magnitude at the estuary mouth. During the high-river flow regime $(2), \tau_{1,4}$ maintains the same longitudinal profile and significantly increases so as to become the dominant process in these conditions.

As can be observed in panels (d), (e), and (i) of figure 7, the LAPE transports due to differential advection and dispersion also have an important role in the balance. Transport values due to longitudinal dispersion are greater near the mouth and decrease upstream. In low-river flow conditions, the transport median value approaches $1.3 \cdot 10^{4} \mathrm{Wm}^{-1}$ in spring tides and is about half that value in neap tides. This shows that dispersive transport is very important in the bottom third of the estuary with a contribution that in certain conditions reaches $30 \%$ of the total transport. Transport induced by differential advection of the average terms is the second dominant process in magnitude during (2), and is comparable to the dispersive transport, $\tau_{5}$. After kilometer 35.3, transport induced by the differential advection of the mean terms and dispersion practically disappears.
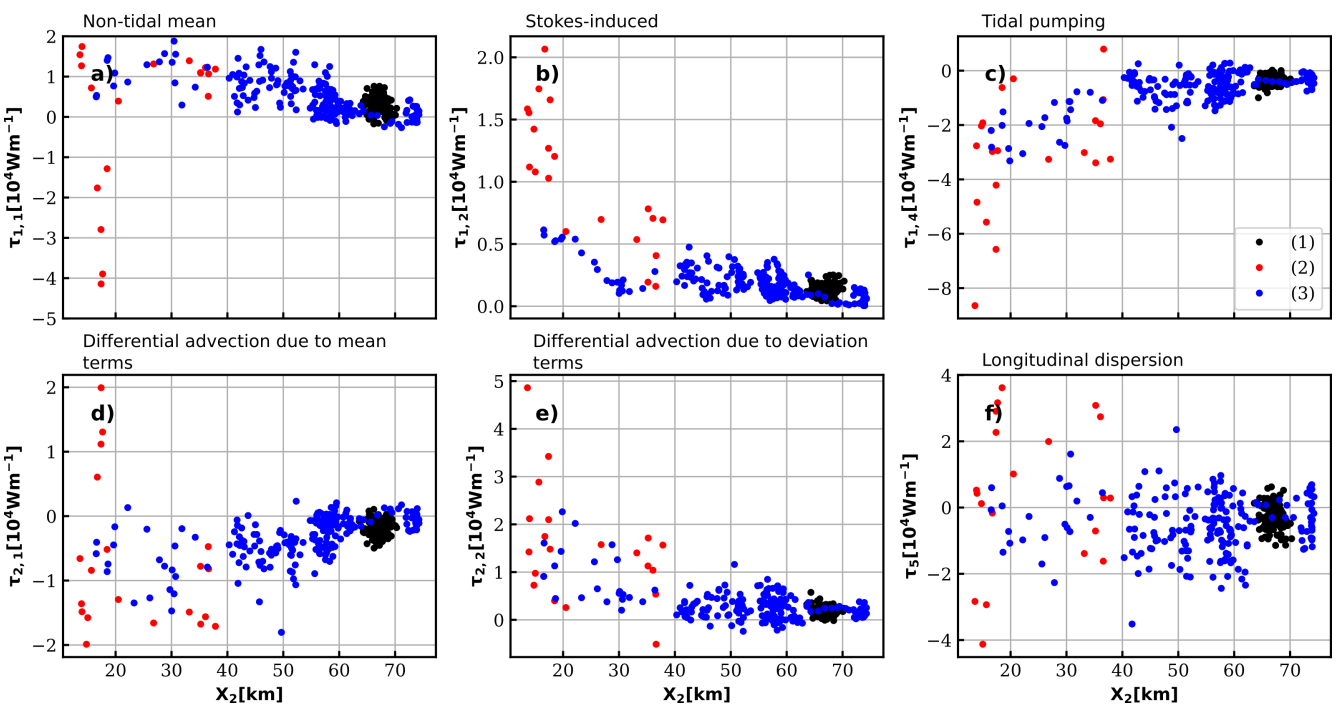

Figure 8. Net-estuarine transports of LAPE versus salt intrusion (2-psu isohaline). a) Nontidal mean advection; b) Stokes advection; $c$ ) tidal pumping advection due to the correlation between currents, elevations and densities; $d$ ) differential advection due to mean terms; e) differential advection due to deviation terms; and, f) longitudinal dispersion. Colors refer to normal conditions (black), high-river flow (red), and post-riverflood (blue) conditions. Positive values are upstream.

The contribution of the surface solar radiation and mixing terms to $\phi$-transport (panels (f), (g), and (h) of figure 7) is not significant. In the Delaware estuary studied in Garvine 
and Whitney (2006) and Rice et al. (2008), the solar radiation and tidal and wind mixing $\phi$-transports are significant buoyancy terms. On the other hand, in the GRE case, the contribution of these terms are not significant because they depend on the surface area, and the boxes considered in the model (see Table 1) are two order of magnitude smaller than the surface area of the Delaware estuary $\left(2.1 \cdot 10^{9} \mathrm{~m}^{2}\right.$, Table 2 in GW2006).

Figure 8 shows the most significant net LAPE transports and their relation to the 2 -psu isohaline in different hydraulic regimes. The magnitude of $\tau_{i}$ decreased upstream because the longitudinal density distribution depends to a great extent on the salinity of the estuary. This behavior is similar to that of the salt transport observed in DíezMinguito et al. (2013). As can be observed, salt intrusion due to the river flow (ReyesMerlo et al., 2013) is linked to LAPE transports. Although the relation between both variables is different for each transport, certain similarities can be observed. Firstly, in normal conditions (1), the absolute transport value does not reach $10^{4} \mathrm{Wm}^{-1}$ and the salt intrusion remains between kilometers 63 and 70. In high-river flow conditions (2), the salt intrusion travels approximately to kilometer 12 . Insofar as their absolute value, transports are maximum although the non-tidal mean advective moves seaward the same as the tidal pumping, Stokes transport, and differential advectives move upstream. LAPE transport due to longitudinal dispersion is a special case because during (2), its magnitude increases in absolute value. Nevertheless, its dependence on the spring and neap tide cycles is important and dispersion increases its variability and maintains its mean value close to zero. During the recovery stage (3), the salt intrusion moves from the estuary mouth upstream and transports regain their values in (1).

Averaged $\phi$-transports, $\tau_{e}$ in eq. (13) were compared with values obtained by GW2006 in the Delaware estuary. In normal conditions, the mean LAPE transport in the GRE, ranged from -1 to $1 \cdot 10^{4} \mathrm{Wm}^{-1}$. In fact, all individual transport modes were found to have similar magnitude $\sim 10^{4} \mathrm{Wm}^{-1}$. During the high-river flow regime, it is observed that the values of individual transports do depend significantly on the flow conditions even though the order of magnitude of $\tau_{e}$ hardly differs from its value in normal conditions. Furthermore, the order of magnitude of the mean transport coincides with the estimates made by Garvine and Whitney (2006) for high-river flows in the Delaware. This occurs because in our model the transport associated with tidal pumping compensates the transport associated with longitudinal dispersion and differential advection. This first term was not considered in Garvine and Whitney (2006).

\section{Discussion}

This study adopted the definition of the longitudinal anomaly of the potential energy in GW2006 and extended it to the zone of tidal river reaches by segmenting the estuary in stretches. The basic physics premises used led to the derivation of a general balance equation (eq. (8)). In realistic scenarios such as this one, balances are determined by only a few terms that can be different in time and space (Díez-Minguito et al., 2013; Burchard \& Hofmeister, 2008). The initial hypotheses of a weakly stratified or well-mixed estuary of limited width allowed us to simplify the LAPE balance equation in the GRE for a box and average it in a tidal cycle (eq. (10)). The model includes the major intratidal processes in the GRE. The non-linear terms that appeared from the equation of state for sea water were neglected because their influence under weakly stratified to well-mixed conditions is limited. In addition, adiabatically corrected temperature and density (i.e., potential temperature and density, respectively), do not play a role in the GRE, where mean depths are about $7 \mathrm{~m}$. However, these terms could be important in stratified estuaries. It is worth to note that the vertical mixing of density is expressed in terms of eddy diffusivity, and it is simplified with empirical mixing terms at a subtidal scale (van Aken, 1986; Simpson, 1981; Simpson \& Bowers, 1981; Simpson et al., 1990). A more rigorous definition of the mixing terms would require the analysis of high resolution spatial and temporal measurements that is out of the scope of this study. 
The longitudinal variability of LAPE and of $\phi$-transports in other fluvial regimes is evident as reflected in the previous analyses. In the low-river flow regime (1), the time variability of the density in neap and spring tides modulated the LAPE field and its transports all along the estuary. Althoug in our study, $\tau$ includes mass anomaly fluxes, the results show alterations similar to those observed in mass fluxes in other estuaries (Vaz et al., 1989), where the alterations were caused by the turbulence modulation induced by tidal currents, basically in fortnightly cycles. The longitudinal variability of $\tau$ produced convergence regions that corresponded to at least one of the ETMs, more specifically, to the one located near $\sim 17 \mathrm{~km}$ (Díez-Minguito et al., 2014). The net estuary transport was positive in box 1 and negative in 2, 3, and 4 during spring tides, whereas the opposite occurred during neap tides. Nevertheless, the magnitude of the net transport decreased considerably in neap tides in the box of the estuary mouth compared to its value in spring tides. It is striking that the same did not occur in high riverflows (2), where the net transport was directed upstream. Nor did it occur in the post-riverflood recovery (3), where the transport at the estuary mouth had the same magnitude in spring tides and neap tides, which mutually compensate each other.

After intermediate fluvial discharges (i.e. flows that are neither low nor high) of flow $Q \simeq 100 \mathrm{~m}^{3} \mathrm{~s}^{-1}$, there was a slight increase in the contribution of the $\phi$-transport associated with tidal pumping. If those pulsed discharges continued during the fortnightly semi-cycle, the magnitude of the Stokes-induced transport significantly decreased in the lower stretch of the estuary (boxes 1 to 3 ). This reduction in magnitude was apparently caused by the movement of the salt intrusion towards the estuary mouth (Reyes-Merlo et al., 2013). The phase lag between elevations and tidal currents, which to a great extent controls the Stokes transport, was not altered by these intermediate discharges.

During the high-river flow episodes (2), the longitudinal profile of $\rho$ was constant inside the estuary and approximately equal to the freshwater density. As a result, the LAPE was minimum in these conditions except at the estuary mouth where it was at its maximum. This situation mainly intensified the magnitudes of the non-tidal mean advective transport and dispersive transport, which was expected. However, it also significantly increased the LAPE transports associated with tidal pumping and differential advection. For this reason, these contributions cannot be ignored in the GRE in highriver flow conditions. These results widen the vision of the GRE and extend it to other hydraulic regimes since in previous studies (Díez-Minguito et al., 2013, 2014), only transports in low-river flow conditions were considered.

During the initial stages of the post-riverflood recovery phase (3), differential advection terms and longitudinal dispersion terms were positive (upstream) near the estuary mouth. This may suggest that there are mechanisms that control the recovery of the LAPE in the estuary, such as the differential advection or the strain-induced periodic stratification (Simpson et al., 1990). However, more research is needed to confirm this possibility.

The influence of sediment suspension was also relevant in the post-riverflood recovery phase. The sediment that was suspended with the discharge remained so because of the turbulence generated by the tidal currents (Losada et al., 2017). The high concentration of suspended solids during the recovery phase was reflected in greater time fluctuations of the LAPE and its transports. The larger difference between neap and spring tides also increased the landward transport of the tidal pumping (Scully \& Friedrichs, 2007) in boxes 2 and 3 .

In addition, the increase in the non-tidal mean $\phi$-transport in the same boxes could be promoting salt transport towards the estuary. Erosion and suspension of the bed sediment favored tidal suspension (Van Leussen \& Dronkers, 1988). Along with this, $\phi$-transport due to longitudinal dispersion became significant during the recovery phase. At the intratidal scale, these conditions created periods during which stratification-induced tur- 
bulence decreased, which indicated an increase in the capacity to retain suspended sediment (Geyer, 1993; Jay \& Musiak, 1996).

As for the applicability of the model, it should be mentioned that in the theoretical development of the equation (9), the estuary is assumed to be weakly stratified. The observations show that the vertical density variability, whether in low-river or high-river flow conditions, ranges from -1.20 to $0.60 \mathrm{~kg} \cdot \mathrm{m}^{-3}$ (Table 1), which justifies this hypothesis. The second hypothesis is that transversal processes are negligible. This hypothesis is quantified in the Kelvin $\left(K_{e}\right)$ and Ekman $\left(E_{k}\right)$ numbers parameter space (ValleLevinson, 2008). The channel width is related to the internal Rossby radius of deformation through the Kelvin number whereas the Ekman number establishes the relation between the viscosity and Coriolis forces. For the mean value of the vertical eddy viscosity coefficient, typical of the GRE $\sim 3.3 \cdot 10^{-4} \mathrm{~m}^{2} \mathrm{~s}^{-1}$ (Reyes-Merlo et al., 2013), values, $K_{e} \sim-2$ and $E_{k} \sim-2.5$, clearly signal a vertically-sheared exchange. Near the estuary mouth, where channel widths are greater and where the values of the vertical eddy viscosity coefficient are $\sim 1.2 \cdot 10^{-3} \mathrm{~m}^{2} \mathrm{~s}^{-1}\left(K_{e} \sim-2\right.$ and $\left.E_{k} \sim-1.25\right)$, a certain degree of lateral variability is expected.

Finally, this study highlights the dependence of the LAPE on the following: (i) origin of the forcing agent; (ii) along-estuary position; (iii) neap and spring tide cycles; and (iv) hydraulic regime. A snapshot of the LAPE along the estuary provides information about the hydrodynamic and mixing conditions of the estuary and could be useful for the management and regulation of the freshwater flow in the head dam. Its use would allow estuary management at the subtidal and local scale (e.g. freshwater discharges in certain stretches of the estuary by taking advantage of the irrigation network).

\section{Conclusions}

The objective of this study was to analyze the spatiotemporal evolution of estuarine processes within the framework of a LAPE box-averaged approach. For this purpose, we developed a dynamic equation of the longitudinal anomaly of the potential energy at the subtidal scale. This equation includes the non-tidal mean advective and Stokesinduced LAPE transport, as well as empirical approximations of the tidal vertical turbulent mixing and the mixing due to wind and solar radiation. In addition, this research extends previous work by including the influence of (i) longitudinal dispersion; (ii) tidal pumping associated with cross-correlations between density, elevations, and currents; and (iii) differential advection due to depth-mean straining, and non depth-mean straining. The general balance equation was applied to the GRE, whose characteristics allowed for simplification and segmentation in five boxes. The analyzed data pertains to the salinity distribution, temperature, suspended solids, tidal elevation and currents, and fluvial discharges recorded along the estuary over a one-year period (2008-2009) in which lowriver flow, high-river flow, and post-riverflood recovery conditions were found. These observations were used to evaluate the LAPE and transports throughout the GRE. The results can help to better understand the processes in a narrow and shallow water estuary under different hydraulic regimes.

The time variability of LAPE transport in low-river flows was modulated with neap and spring tides. At the estuary mouth, they were in phase with each other, and further upstream, they were out of phase. Time variability in regard to the mean value was similar in spring tides and neap tides $( \pm 10.65 \%)$. The only exception was the Stokes-induced LAPE transport, whose magnitude significantly increased in spring tides. The LAPE transports of all processes in the GRE changed sign on various occasions at approximately kilometers 17 and 35 . This gave rise to transport convergence and divergence zones, respectively. The transport convergence region was consistent with the location of the ETM in previous studies. Transports due to dispersive and differential advection moved upstream from the estuary mouth, whereas the others went seaward. 
In high-river flows, the longitudinal profiles of the LAPE transport were inverted. The opposite was true for tidal pumping, longitudinal dispersion and differential advection of the deviation in regard to the mean terms, which became considerably greater. The convergence and divergence zones of the non-tidal mean advective LAPE transport disappeared as well as those of the Stokes-induced, and differential advection transport because of the mean terms. Tidal pumping exported the LAPE through the estuary mouth, and was thus balanced with the transport associated with the longitudinal dispersion and differential advection because of the deviation terms that import it.

During the post-riverflood recovery, all transport processes intensified except for the Stokes-induced transport. In the vicinity of the tidal river reach, the magnitude of all LAPE transports was no longer significant. The differential advection and longitudinal dispersion terms moved upstream in the estuary mouth, which suggests that they are the terms that recover the LAPE of the estuary. The time variability in these conditions was considerable in the LAPE transport because of the longitudinal dispersion $( \pm 19.49 \%$ of the mean value). The greater difference between neap and spring tides increased the landward transport of tidal pumping in the middle stretch of the estuary. In addition to this, there was a significant increase in the non-tidal mean LAPE transport. In these conditions, the longitudinal gradient of LAPE transport was amplified, which caused the convergence and divergence zones to reappear.

\section{Appendix A Derivation of the LAPE Equation}

The balance equation of the potential energy anomaly in a box (eq. (8)) is obtained by evaluating the dynamic density equation $\mathbf{D}(x, t)$ in one reference position $x$ and another $x_{0}$ and substituting the values in the following expression:

$$
g\left[\underline{\mathbf{D}\left(x_{0}, t\right)} \underline{z}-\underline{\mathbf{D}(x, t) z]}=0,\right.
$$

where $\zeta$ represents the depth average; the term, $\mathbf{D}(x, t)$, is defined by equation 5 , (repeated below to clarify the derivation):

$$
\mathbf{D}(x, z, t)=\partial_{t} \rho+\partial_{x}(u \rho)+\partial_{z}(w \rho)-\partial_{x}\left(k_{x} \partial_{x} \rho\right)-\partial_{z}\left(k_{z} \partial_{z} \rho\right)-\mathbf{S}
$$

where $\mathbf{S}$ includes the density variation due to heat transfer by the surface layer and the resuspension of sediment from the estuary bottom as:

$$
\mathbf{S}=\frac{g \rho \alpha_{w}}{\rho_{0} c_{p}} I e^{-\varepsilon(\eta-z)}+\left(1-\frac{\rho}{\rho_{s}}\right) C \partial_{z}\left(w_{s} C\right)
$$

where non-linear terms that appear from equation of state for sea water are neglected (see eq. (6)); $\alpha_{w}$ is the water expansion coefficient; $c_{p}$ is the heat capacity of the water; $\varepsilon$ is the light absorption along the vertical profile; $w_{s}$ is the sedimentation velocity of the particulated material, assumed to be constant for a given grain size; and, $C$ is the suspended solids concentration. The parameterization of heat transfer follows the LambertBeer Law where $\varepsilon$ is the attenuation coefficient (Ruiz et al., 2013). In shallow basins, a significant portion of solar radiation can reach the bottom where it is transformed into heat (Wiles et al., 2006). By calculating

$$
\begin{aligned}
& g\left(\underline{\mathbf{S}\left(x_{0}, t\right)} \underline{z}-\underline{\mathbf{S}(x, t) z)=-\frac{\alpha_{w} \rho g I}{\rho_{0} c_{p}}}[\right.\left.\left(1-e^{-\varepsilon(\eta-z)}\right) \underline{z}+\left(\varepsilon^{-1}-e^{-\varepsilon(\eta-z)}\left(d+\varepsilon^{-1}\right)\right)\right] \\
&+\frac{w_{s}}{2 d}\left(\left[C^{2}\right]_{\eta}-\left[C^{2}\right]_{-h}+\eta\left[C^{2}\right]_{\eta}+h\left[C^{2}\right]_{-h}-d \underline{C}\right),
\end{aligned}
$$

term $t_{G}$ of eq. (8) is obtained.

The processes related to transversal circulation are negligible in narrow low-friction channels (Valle-Levinson, 2008) and thus dependent on $x, z$, and time $t$. 
For the sake of simplicity, the methodology is applied to the terms on the left of eq. (A2), related to time variation, advection, dispersion, and density mixing. The term most to the left in eq. (8) is further developed in eq. (A5) by applying the chain rule and Leibniz's rule to derivatives with variable limits and kinematic boundary conditions on the water surface $w_{\eta}=\partial_{t} \eta+u_{\eta} \cdot \partial_{x} \eta$, for a fixed bed, $w_{-h}=0$ :

$$
\begin{array}{r}
\int_{-h}^{\eta} z\left[\partial_{t} \rho+\partial_{x}(u \rho)+\partial_{z}(w \rho)-\partial_{x}\left(k_{x} \partial_{x} \rho\right)-\partial_{z}\left(k_{z} \partial_{z} \rho\right)\right] d z= \\
\partial_{t} \int_{-h}^{\eta} z \rho d z+\partial_{x} \int_{-h}^{\eta}(z u \rho) d z-\int_{-h}^{\eta} w \rho d z-\partial_{x} \int_{-h}^{\eta} z k_{x} \partial_{x} \rho d z+\int_{-h}^{\eta} k_{z} \partial_{z} \rho d z \\
+\left[(z \rho)_{\eta} \partial_{t} \eta+(z u \rho)_{\eta} \partial_{x} \eta+(z w \rho)_{\eta}\right]+\left[(z \rho)_{-h} \partial_{t} h+(z u \rho)_{-h} \partial_{x} h+(z w \rho)_{-h}\right]- \\
\left(z k_{x} \partial_{x} \rho\right)_{\eta} \partial_{x} \eta-\left(z k_{x} \partial_{x} \rho\right)_{-h} \partial_{x} h+\left(z k_{z} \partial_{z} \rho\right)_{\eta}+\left(z k_{z} \partial_{z} \rho\right)_{-h}= \\
\partial_{t}(d z \rho)+\partial_{x}(d z u \rho)-(d \underline{w \rho})+\partial_{x}\left(d z k_{x} \partial_{x} u \rho\right)+\left(d k_{x} \partial_{z} \rho\right) \\
\left(z k_{x} \partial_{x} \rho\right)_{\eta} \partial_{x} \eta+\left(\overline{z k_{x}} \partial_{x} \rho\right)_{-h} \partial_{x} h-\left(z k_{z} \partial_{z} \rho\right)_{\eta}-\left(z k_{z} \partial_{z} \rho\right)_{-h},
\end{array}
$$

where subindexes $\eta$ and $-h$ indicate that the terms are evaluated in $z=\eta$ and $z=-h$. Inserting eqs. (7) and (A5) in the eq. (A1),

$$
\begin{array}{r}
\partial_{t}\left(g\left(\underline{\rho_{0}} \underline{z}-\underline{\rho z}\right)\right)+\partial_{x}\left(g\left(\underline{u \rho_{0}} \underline{z}-\underline{u \rho z}\right)\right)-g(\underline{w \rho}) \\
-g \underline{k_{z} \partial_{z} \rho}+g d^{-1}\left(\underline{z} k_{z} \partial_{z} \rho\right)^{\eta}-g d^{-1}\left(\underline{z} k_{z} \partial_{z} \rho\right)^{-h}+\partial_{x}\left(g\left[k_{x} \partial_{x} \underline{\rho}\right](z-\underline{z})\right) \\
+g d^{-1}(\underline{z}-\eta)\left(k_{x} \partial_{x} \rho\right)^{\eta} \partial_{x} \eta-g d^{-1}(\underline{z}+h)\left(k_{x} \partial_{x} \rho\right)^{-h} \partial_{x} h .
\end{array}
$$

A general variable $\zeta=\zeta+\zeta_{v}$ is composed of the sum of a depth-averaged value and its deviation. When this variable is applied in the equation, equation (8) is obtained. As in Burchard and Hofmeister (2008) and De Boer et al. (2008), no hypothesis has been formulated regarding the form of the longitudinal velocity profile.

\section{Acknowledgments}

This research was partially funded by the Campus de Excelencia Internacional del $\operatorname{Mar}(C e i-M A R)$ and the Spanish Ministry of Economy and Competitiveness, Project PIRATES (CTM2017-89531-R). It was also supported by AQUACLEW. Project AQUACLEW is part of ERA4CS, an ERA- NET initiated by JPI Climate, and funded by FORMAS (SE), DLR (DE), BMWFW (AT), IFD (DK), MINECO (ES), ANR (FR) with cofunding by the European Commission. Datasets for this research are available in this intext data citation reference: Navarro et al. (2019) [Creative Commons Attribution 4.0 International license, open access right]. This study is a tribute to the memory of Richard W. Garvine, whose research was the inspiration for our work.

\section{References}

Austin, J. A. (2002). Estimating the mean ocean-bay exchange rate of the chesapeake bay. Journal of Geophysical Research: Oceans, 107(C11).

Becherer, J., Flöser, G., Umlauf, L., \& Burchard, H. (2016). Estuarine circulation versus tidal pumping: Sediment transport in a well-mixed tidal inlet. Journal of Geophysical Research: Oceans, 121 (8), 6251-6270.

Bowden, K. (1981). Turbulent mixing in estuaries. Ocean Management, 6(2-3), 117135.

Burchard, H., \& Hetland, R. D. (2010). Quantifying the contributions of tidal straining and gravitational circulation to residual circulation in periodically stratified tidal estuaries. Journal of Physical Oceanography, 40(6), 1243-1262.

Burchard, H., \& Hofmeister, R. (2008). A dynamic equation for the potential energy anomaly for analysing mixing and stratification in estuaries and coastal seas. Estuarine, Coastal and Shelf Science, 77(4), 679-687. 
Burchard, H., Schuttelaars, H. M., \& Ralston, D. K. (2018). Sediment trapping in estuaries. Annual review of marine science, 10, 371-395.

De Boer, G. J., Pietrzak, J. D., \& Winterwerp, J. C. (2008). Using the potential energy anomaly equation to investigate tidal straining and advection of stratification in a region of freshwater influence. Ocean Modelling, 22(1-2), 1-11.

Díez-Minguito, M., Baquerizo, A., de Swart, H., \& Losada, M. (2014). Structure of the turbidity field in the guadalquivir estuary: Analysis of observations and a box model approach. Journal of Geophysical Research: Oceans, 119(10), 7190-7204.

Díez-Minguito, M., Baquerizo, A., Ortega-Sánchez, M., Navarro, G., \& Losada, M. (2012). Tide transformation in the guadalquivir estuary (sw spain) and process-based zonation. Journal of Geophysical Research: Oceans, 117(C3).

Díez-Minguito, M., Contreras, E., Polo, M., \& Losada, M. (2013). Spatio-temporal distribution, along-channel transport, and post-riverflood recovery of salinity in the guadalquivir estuary (sw spain). Journal of Geophysical Research: Oceans, 118(5), 2267-2278.

Ganju, N. K., Brush, M. J., Rashleigh, B., Aretxabaleta, A. L., Del Barrio, P., Grear, J. S., ... others (2016). Progress and challenges in coupled hydrodynamic-ecological estuarine modeling. Estuaries and coasts, 39(2), $311-332$

Garvine, R. W., \& Whitney, M. M. (2006). An estuarine box model of freshwater delivery to the coastal ocean for use in climate models. Journal of Marine Research, 64 (2), 173-194.

Geyer, W. R. (1993). The importance of suppression of turbulence by stratification on the estuarine turbidity maximum. Estuaries, 16(1), 113-125.

Hamilton, P., Gunn, J. T., \& Cannon, G. A. (1985). A box model of puget sound. Estuarine, Coastal and Shelf Science, 20(6), 673-692.

Hansen, D. V., \& Rattray, M. (1966). New dimensions in estuary classification. Limnology and Oceanography, 11(3), 319-326.

Hobbie, J. E. (2000). Estuarine science: the key to progress in coastal ecological research. Estuarine science: A synthetic approach to research and practice, 111.

Hofmeister, R., Burchard, H., \& Bolding, K. （2009). A three-dimensional model study on processes of stratification and de-stratification in the limfjord. Continental Shelf Research, 29(11-12), 1515-1524.

Jay, D. A., \& Musiak, J. D. (1994). Particle trapping in estuarine tidal flows. Journal of Geophysical Research: Oceans, 99(C10), 20445-20461.

Jay, D. A., \& Musiak, J. D. (1996). Internal tidal asymmetry in channel flows: Origins and consequences. Coastal and Estuarine Studies, 211-249.

Jay, D. A., \& Smith, J. D. (1990). Residual circulation in shallow estuaries: 2. weakly stratified and partially mixed, narrow estuaries. Journal of Geophysical Research: Oceans, 95(C1), 733-748.

Leschine, T. M., Ferriss, B. E., Bell, K. P., Bartz, K. K., MacWilliams, S., Pico, M., \& Bennett, A. K. (2003). Challenges and strategies for better use of scientific information in the management of coastal estuaries. Estuaries, 26(4), $1189-1204$.

Losada, M., Díez-Minguito, M., \& Reyes-Merlo, M. (2017). Tidal-fluvial interaction in the guadalquivir river estuary: Spatial and frequency-dependent response of currents and water levels. Journal of Geophysical Research: Oceans, 122(2), 847-865.

Monismith, S. G., Kimmerer, W., Burau, J. R., \& Stacey, M. T. ～(2002). Structure and flow-induced variability of the subtidal salinity field in northern san francisco bay. Journal of Physical Oceanography, 32(11), 3003-3019.

Navarro, G., Gutiérrez, F. J., Díez-Minguito, M., Losada, M. A., \& Ruiz, J. (2011). Temporal and spatial variability in the guadalquivir estuary: a challenge for 
real-time telemetry. Ocean Dynamics, 61(6), 753-765.

Navarro, G., Ruiz, J., Cobos, M., Baquerizo, A., Díez-Minguito, M., OrtegaSanchez, M., \& Losada, M. n. $\quad$ (2019, September). Atmospheric, hydrodynamic and water quality observations from environmental-quality stations, water level sensors, acoustic Doppler velocimeters, and meteorological stations located at the Guadalquir river estuary (2008 - 2010). Retrieved from https://doi.org/10.5281/zenodo.3459610 doi: 10.5281/zenodo.3459610

Officer, C. B. (1980). Box models revisited. Estuarine and wetland processes with emphasis on modeling, 65-114.

Officer, C. B. (2013). Physical oceanography of estuarines. john wiley.

Padilla, E. M., Díez-Minguito, M., Ortega-Sánchez, M., \& Losada, M. A. A subtidal model of temperature for a well-mixed narrow estuary: the guadalquivir river estuary (sw spain). Estuaries and coasts, 39(3), 605-620.

Reyes-Merlo, M. Á., Díez-Minguito, M., Ortega-Sánchez, M., Baquerizo, A., \& Losada, M. Á. (2013). On the relative influence of climate forcing agents on the saline intrusion in a well-mixed estuary: Medium-term monte carlo predictions. Journal of Coastal Research, 65(sp2), 1200-1205.

Reyes-Merlo, M. Á., Ortega-Sánchez, M., Díez-Minguito, M., \& Losada, M. (2017). Efficient dredging strategy in a tidal inlet based on an energetic approach. Ocean and Coastal Management, 25(3-4), 37 - 52. doi: 10.1016/0378-3839(95)00008-Y

Rice, A. E., Whitney, M. M., Garvine, R. W., \& Huq, P. (2008). $\quad$ Energetics in delaware bay: Comparison of two box models with observations. Journal of Marine Research, 66(6), 873-898.

Ruiz, J., Macías, D., Losada, M., Díez-Minguito, M., \& Prieto, L. (2013). A simple biogeochemical model for estuaries with high sediment loads: Application to the guadalquivir river (sw iberia). Ecological modelling, 265, 194-206.

Ruiz, J., Polo, M. J., Díez-Minguito, M., Navarro, G., Morris, E. P., Huertas, E., ... Losada, M. A. (2015). The guadalquivir estuary: a hot spot for environmental and human conflicts. In Environmental management and governance (pp. 199-232). Springer.

Scully, M. E., \& Friedrichs, C. T. (2007). Sediment pumping by tidal asymmetry in a partially mixed estuary. Journal of Geophysical Research: Oceans, 112(C7).

Simpson, J. (1981). The shelf-sea fronts: implications of their existence and behaviour. Phil. Trans. R. Soc. Lond. A, 302(1472), 531-546.

Simpson, J. (1997). Physical processes in the rofi regime. Journal of marine systems, 12(1-4), 3-15.

Simpson, J., \& Bowers, D. (1981). Models of stratification and frontal movement in shelf seas. Deep Sea Research Part A. Oceanographic Research Papers, 28(7), $727-738$.

Simpson, J., Brown, J., Matthews, J., \& Allen, G. (1990). Tidal straining, density currents, and stirring in the control of estuarine stratification. Estuaries and Coasts, 13(2), 125-132.

Simpson, J., \& Hunter, J. (1974). Fronts in the irish sea. Nature, 250(5465), 404.

Simpson, J., \& Sharples, J. (2012). Introduction to the physical and biological oceanography of shelf seas. Cambridge University Press.

Simpson, J., Sharples, J., \& Rippeth, T. (1991). A prescriptive model of stratification induced by freshwater runoff. Estuarine, Coastal and Shelf Science, 33(1), 23-35.

Sun, Q., Whitney, M. M., Bryan, F. O., \& Tseng, Y.-h. (2017). A box model for representing estuarine physical processes in earth system models. Ocean Modelling, 112, 139-153.

Valle-Levinson, A. (2008). Density-driven exchange flow in terms of the kelvin and ekman numbers. Journal of Geophysical Research: Oceans, 113(C4). 
Valle-Levinson, A. (2010). Contemporary issues in estuarine physics. Cambridge University Press.

van Aken, H. M. (1986). The onset of seasonal stratification in shelf seas due to differential advection in the presence of a salinity gradient. Continental Shelf Research, 5(4), 475-485.

Van Leussen, W., \& Dronkers, J. (1988). Physical processes in estuaries: An introduction. In Physical processes in estuaries (pp. 1-18). Springer.

Vaz, R. A. N., Lennon, G. W., \& de Silva Samarasinghe, J. R. (1989). The negative role of turbulence in estuarine mass transport. Estuarine, Coastal and Shelf Science, 28(4), 361-377.

Wiles, P. J., van Duren, L. A., Häse, C., Larsen, J., \& Simpson, J. H. (2006). Stratification and mixing in the limfjorden in relation to mussel culture. Journal of marine systems, 60(1-2), 129-143.

Yang, W., Wei, H., \& Zhao, L. (2017). Observations of tidal straining within two different ocean environments in the east china sea: Stratification and near-bottom turbulence. Journal of Geophysical Research: Oceans, 122(11), 8876-8893.

Zhao, Q., Ren, Y., \& Wang, J. X. (2018). Temporal and spatial characteristics of potential energy anomaly in lake taihu. Environmental Science and Pollution Research, 1-10. 